Omar J. Portillo-Castillo / Rocío Castro-Ríos / Abelardo Chávez-Montes² / Azucena González-Horta ${ }^{2}$ / Norma Cavazos-Rocha' / Noemí H. Waksman de Torres ${ }^{1}$ / Marsela Garza-Tapia ${ }^{1}$

\title{
Developments of solid-phase microextraction fiber coatings for environmental pharmaceutical and personal care products analysis
}

\author{
${ }^{1}$ Departamento de Química Analítica, Facultad de Medicina, Universidad Autónoma de Nuevo León, 64460, Monterrey, Nuevo \\ León, Mexico, E-mail: marselagarzao7@hotmail.com \\ ${ }^{2}$ Departamento de Química, Facultad de Ciencias Biológicas, Universidad Autónoma de Nuevo León, 66451, San Nicolás de los \\ Garza, Nuevo León, Mexico
}

\begin{abstract}
:
Solid-phase microextraction (SPME) is a sample preparation technique with many applications that is being continuously developed. In this technique, the type of fiber coating plays a crucial role for extraction efficiency. Currently available commercial coatings have certain drawbacks that have been overcome by the development of new coatings based on novel materials; these have improved the efficiency of extraction, selectivity and stability of commercial coatings. Pharmaceutical and personal care products (PPCPs) are one of the most important groups of emerging contaminants; however, some studies suggest that these compounds can cause adverse health effects. No official monitoring protocols for these compounds are currently available, so the establishment of analytical methods that allow their determination in environmental samples is required. The complexity of environmental samples together with the low concentration levels of these compounds makes necessary the use of sample preparation techniques capable of removing interferences, as well as preconcentrated analytes, and SPME is a very promising alternative to achieve this. This review describes the recent developments in SPME with classical and novel coatings and its applications for PPCP determination in environmental samples.
\end{abstract}

Keywords: environmental samples, fiber coatings, pharmaceutical and personal care product (PPCP), solidphase microextraction (SPME)

DOI: $10.1515 /$ revac-2017-0018

Received: August 18, 2017; Accepted: December 27, 2017

\section{Introduction}

Pharmaceutical and personal care products (PPCPs) are a wide group of substances that includes human and animal pharmaceutical products; contrast media for medical diagnosis; disinfectants, preservatives and fragrances used in personal care products; and household chemical products (Birch et al. 2015 and Lin, Yu, and Chen 2016).

Recently, concern about PPCPs has grown because of their extensive use and the potential negative effects that these compounds represent for both the environment and human health. Furthermore, some of these chemicals are believed to be responsible for some types of cancer and hormonal disruption in animals (Gracia et al. 2012). Recent research has suggested that these compounds do not need to be persistent, as their high use rates make them constantly present in the environment (You et al. 2015). However, the omnipresence of PPCPs is due to not only indiscriminate use, but also chemical properties such as a polar or hydrophilic nature; these features make elimination from aqueous matrixes difficult. Therefore, these compounds can survive processing in wastewater treatment plants, eventually being distributed through effluents to reach flora, fauna and aquifers. In the same way, PPCPs are not eliminated in drinking water purification plants, which can lead to unintentional exposure in humans (Ellis 2006 and Bu et al. 2013).

PPCPs have been detected in surface, ground, drinking and wastewater, in sewage sludge and sediments (McClellan and Halden 2010 and Papageorgiou, Kosma, and Lambropoulou 2016) and in biological tissues and fluids (Jiménez et al. 2014 and Tanoue et al. 2014). Levels of these contaminants depend on both the chemical substance and the sample, but can vary from $\mu \mathrm{g} \mathrm{kg}^{-1}$ to $\mathrm{ng} \mathrm{kg}^{-1}$ (Teo, Coleman, and Khan 2016). At present, 
although there is no international or national legislation specific for PPCP residue control, the U.S. Environmental Protection Agency has proposed several methods for the analysis of these kinds of compounds in different matrixes (EPA Method 16942007 and EPA Method 198 2007).

Screening, identification and quantitation of PCPPs are usually carried out using liquid chromatography with ultraviolet-visible or diode-array detectors, and to a lesser extent, gas chromatography (GC) with flame ionization detection (Oliveira et al. 2015). However, due to the sample complexity and the wide range of chemical properties of PPCPs, the analysis of this group of compounds is difficult; the use of more selective and sensible detectors is therefore mandatory. GC coupled to mass spectrometry (GC-MS) is a very reproducible, robust and relatively simple technique that has been used for a long time for the routine analysis of contaminants. Nevertheless, the analysis of chemical substances bearing polar functional groups is one of the major disadvantages of GC-MS, as derivatization steps to increase volatility and reduce polarity should be included, resulting in long and laborious analytical methods (Aznar et al. 2016). LC-MS couplings make it possible to simultaneously determine a higher number of compounds, but because of the polarity differences, these methods are usually lengthy and expensive. Thus, one of the main challenges is the development of methods capable of analyzing a great number of compounds in shorter periods of time (Kasprzyk, Dinsdale, and Guwy 2008).

Solid-phase extraction (SPE) is the sample preparation technique most commonly used in the analysis of PPCPs (Celano et al. 2014), and some of these compounds can be easily preconcentrated using traditional reverse-phase SPE cartridges (Al-Qaim et al. 2014). Nevertheless, PPCPs include a number of molecules with a wide polarity range that are not well extracted with conventional cartridges, making the use of alternative extraction phases such as those combining ionic exchange-hydrophobic or hydrophilic-hydrophobic balance interactions necessary. SPE is not considered a good alternative for multi-class analysis, as its procedures are usually lengthy and tedious, require large volumes of organic solvents and samples and have low efficiencies (Buchberger 2011).

One of the most important tendencies in analytical chemistry is that toward minimization of sample, solvent and residue amounts, and several highly efficient microextraction techniques have been developed. For PPCP analysis, a number of procedures using microextraction techniques using mostly solid-phase microextraction (SPME) have been proposed (Robles et al. 2013), even though techniques such as stir-bar sorptive extraction (Bratkowska et al. 2011 and Gilart et al. 2013) or dispersive liquid-liquid microextraction (Souza et al. 2016) have been employed. Once again, difficulties faced in using these techniques are related to the wide range of chemical compounds included in the PPCP group that require alternative extraction phases to improve extraction efficiencies.

The purpose of this review is to describe recent developments regarding SPME fiber coatings for the determination of PPCPs in environmental samples, as many of these new materials have been able to overcome some of the problems commonly encountered during the analysis of these emerging contaminants. This review gives an overview of the research published from 2008 to 2017.

\section{Solid-phase microextraction}

SPME is a microextraction technique developed by Pawliszyn et al. that became commercially available in the 1990s (Arthur and Pawliszyn 1990). Similar to other microextraction techniques, SPME is a non-exhaustive process in which analytes partition the sample and extraction phase. When equilibrium between the phases is reached, the concentration of analytes in the extraction phase remains constant and is proportional to the concentration of analytes in the sample (Pawliszyn 2010). SPME is usually carried out using fused silica or metallic fibers coated with the extraction phase. Nevertheless, alternative approaches in which, for instance, the extraction phase is fixed on the inner walls of a capillary tube or a vessel, or covering the exterior of magnetic stirring bars, have been proposed (Mehdinia and Aziz 2013a).

In SPME, extraction and preconcentration of analytes are carried out simultaneously, but it is also possible to carry out sampling in the same step. In addition, SPME usually involves simple procedures, reduces sample manipulation, is useful for solid, liquid and gas samples, is practically solvent-free, can be automated and is relatively inexpensive because the fibers are reusable (Pan et al. 2014).

All SPME procedures include two main steps: analyte extraction and further desorption of extracted compounds for the final analysis. Extraction can be achieved by direct immersion (DI) or in the headspace (HS) over the sample (Kataoka and Saito 2011), while desorption is mostly done by exposing fibers to high temperatures in the GC injector, although this can also be done by immersing fibers in a suitable solvent (Płotka et al. 2015).

The physicochemical nature and thickness of fiber coatings have a strong influence on the distribution of analytes between the sample matrix and the extraction phase, which affects the extraction efficiency, selectivity and reproducibility of the analysis. Fiber selection takes the molecular weight, polarity and volatil- 
ity of target compounds into account (Spietelun et al. 2010). Commercial SPME fibers are manufactured by Sigma-Aldrich (St. Louis, MO, USA) and currently nine coatings of various film thicknesses are available. Polydimethylsiloxane (PDMS) is a non-polar extraction phase commonly used in SPME, and fibers are produced with 100, 65 and $7 \mu \mathrm{m}$ film thickness. Polyacrylate (PA) and carbowax-polyethylene glycol are polar and liquid extraction phases that can be obtained with thicknesses of 85 and $65 \mu \mathrm{m}$, respectively. Also, some mixed phases have been developed providing complementary selectivity for PDMS and PA coatings. To date, the available commercial mixed phases are carboxen-polydimethylsiloxane (CAR/PDMS), polydimethylsiloxane-divinylbenzene (PDMS/DVB), divinylbenzene-carboxen-polydimethylsiloxane (DVB/CAR/PDMS), carbowax-divinylbenzene (CW/DVB) and carbowax-templated resin. Although most of the SPME fiber coatings were developed based on stationary GC phases, recently an octadecylsilane (C18) fiber probe began to be commercialized that is intended to the extraction of relatively polar and non-polar analytes in LC applications (Sigma Aldrich 2017). The number of commercially available phases is still relatively low and almost restricted to non-polar or relatively non-polar compounds. This disadvantage, in addition to the limitations of operation temperatures, the use of solvents and sample composition, has led to the development of new fiber coating materials that allow a broader applicability of this promising technique (Souza, Risticevic, and Pawliszyn 2013 and Wang et al. 2012).

\section{Conventional SPME fiber coatings}

As mentioned above, the chemical nature of analytes must be considered for fiber coating selection. For the analysis of PPCPs from environmental samples, the most commonly used conventional fibers have been PDMS (Basaglia, Pasti, and Pietrogrande 2011), PDMS/DVB (Vallecillos, Borrull, and Pocurull 2013a and Vallecillos, Pocurull, and Borrull 2013b), PA (Naccarato et al. 2014) and DVB/CAR/PDMS (Regueiro et al. 2009) with different coating thicknesses, the main reason being that these fibers are readily available.

Several PPCPs have been determined using conventional SPME fibers in both HS and DI modes. Among the most notable are drug residues (Gil et al. 2009 and Feitosa et al. 2011), UV filters (Negreira et al. 2009 and Y1lmazcan et al. 2015), polycyclic (Wang and Ding 2009) and macrocyclic musks (Vallecillos, Borrull, and Pocurull 2013a and Vallecillos, Pocurull, and Borrull 2013b), parabens and some disinfectants such as triclosan (Regueiro et al. 2009). However, as the available SPME fiber coatings are limited, analytical methods have problems related to selectivity, working temperatures and solvent and matrix incompatibilities. In addition, most fibers show low extraction efficiencies for highly polar and non-volatile compounds (Souza, Risticevic, and Pawliszyn 2013).

As PPCPs include a very heterogeneous group of compounds with a wide range of physicochemical properties, the development of methods for the simultaneous determination of these analytes is still a challenge for analytical chemists. For instance, for the analysis of triclosan, bisphenol A, chlorophenols and some pharmaceutical residues in water samples, Kim, Han, and Choi (2013) evaluated the performance of four commercial fibers (PA, PDMS, PDMS/DVB and CW/TPR). PA and PDMS fibers yielded very low recoveries for all target compounds, while PDMS/DVB coating showed an intermediate extraction efficiency for most target compounds, except for bisphenol A. The best results were obtained using the CW/TPR fibers which gave good recoveries for all analytes. Furthermore, it was observed that solvent desorption was not efficient for polar compounds when using PA and CW/TPR fibers and a cleaning step should be included to avoid carryover.

In order to obtain good recoveries, avoid carryover and prevent losses or modifications of fiber coating, establishing desorption conditions is as important as setting optimal extraction conditions (Torres, Sosa, and Santana 2009). The use of micellar media has been proposed as an alternative approach to the use of organic solvents for analyte desorption. For example, a method using the polyoxyethylene lauryl ether 10 as a surfactant was utilized for fluoroquinolone desorption from a CW/TPR fiber. Micellar media increased the amount of desorbed analytes due to their affinity for surfactants. In addition, micelles enhanced the fluorescent response of analytes by increasing the rigidity of the target molecules (Montesdeoca et al. 2009).

A number of PPCPs have been analyzed using HS-SPME procedures, although this extraction mode has had higher application for fragrances, mainly for polycyclic (Wang and Ding 2009) and macrocyclic musks (Vallecillos, Borrull, and Pocurull 2013a and Vallecillos, Pocurull, and Borrull 2013b). In these cases, thermal desorption is carried out by placing the fibers in the GC injection port.

In general, HS extraction is carried out by heating the sample, as better extraction efficiencies are obtained up to the point at which desorption of analytes is favored. Nevertheless, it is difficult to find a system capable of heating samples uniformly. To overcome this problem, microwave-assisted procedures have been proposed. For instance, Wang and Ding (2009) developed an HS-SPME method for the extraction of six polycyclic synthetic musks using PDMS/DVB fibers $(65 \mu \mathrm{m})$ from wastewater. Samples were microwave irradiated at $180 \mathrm{~W}$, and 
as a result, a reduction in extraction time from 25 to 4 min was achieved. Recoveries ranged from $64 \%$ to $102 \%$ for target analytes (Wang and Ding 2009).

Table 1 and Table 2 present a selection of DI and HS-SPME methods for PPCP analysis using conventional fibers. 


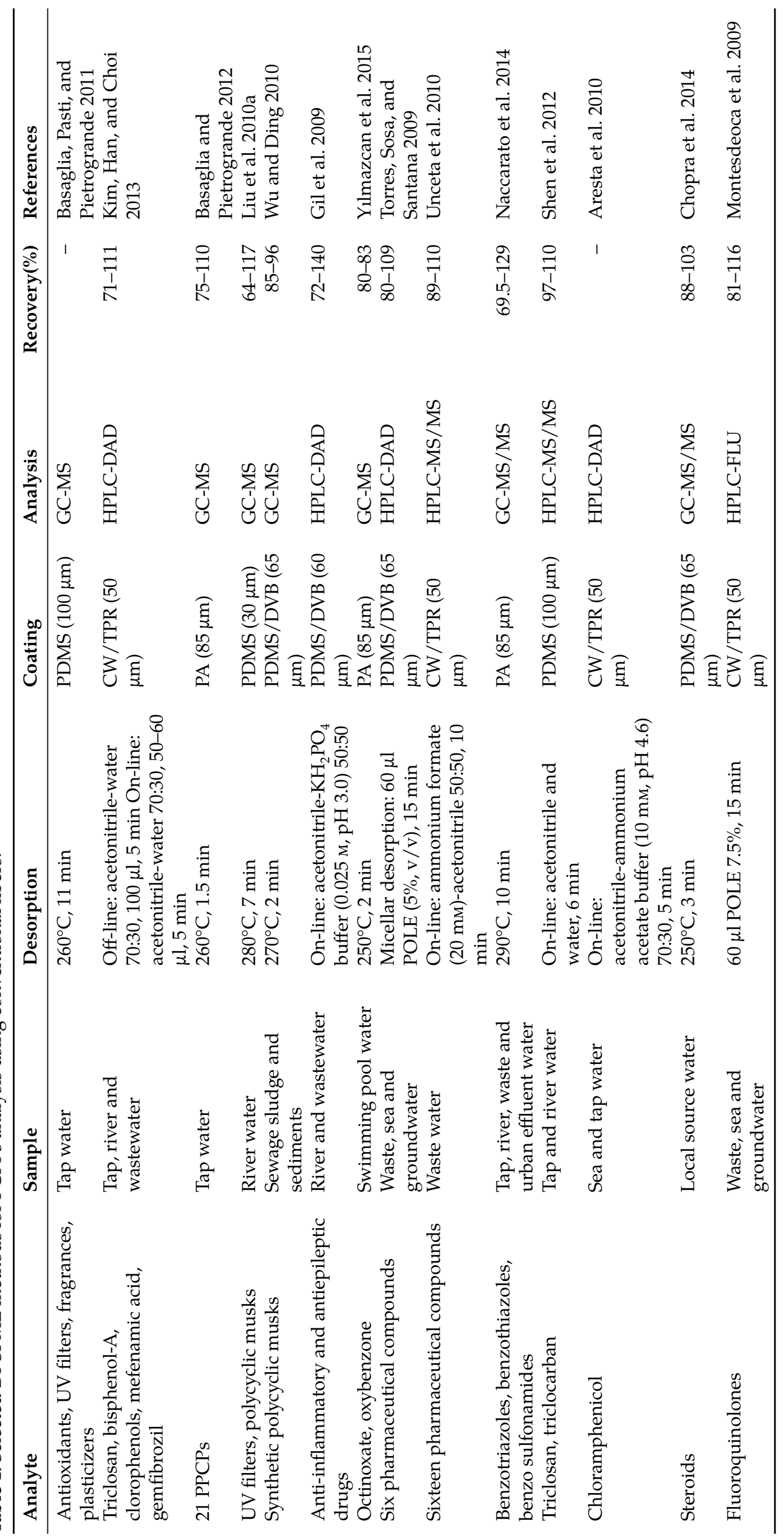




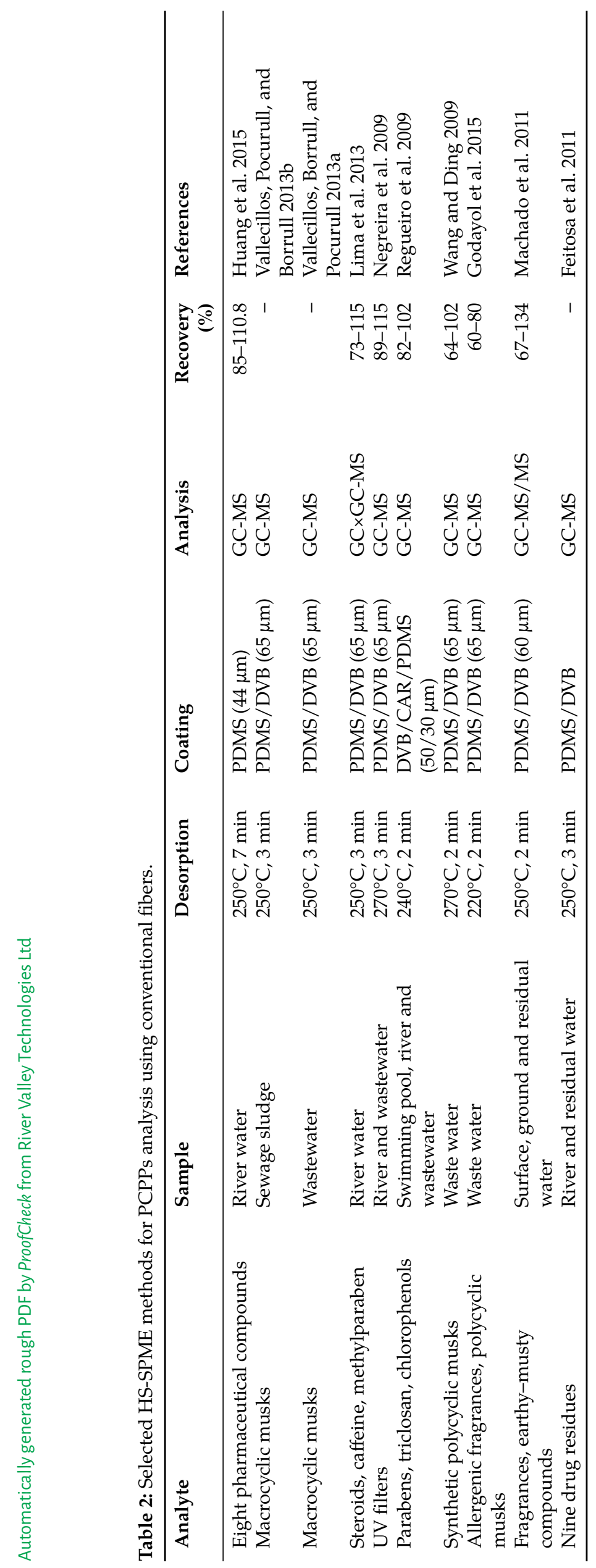


Derivatization has been proposed as an alternative approach to overcome the difficulties encountered during the simultaneous determination of PPCPs. The modification of the chemical structure of the target compounds can be performed at different stages during the analytical process (Merkle, Kleeberg, and Fritsche 2015). In SPME, analyte derivatization can be carried out before, during or after extraction; all these schemes have been reported for PPCP analysis. As an example, for pharmaceutical residue analysis in river water, an intermediate step was included in order to obtain methyl ester derivatives prior to HS-SPME with a PDMS fiber (Huang et al. 2015). Dimethyl sulfate was used as derivatization and the analysis was carried out using GC-MS.

On the other hand, Regueiro et al. (2009) proposed an in situ SPME derivation method for the determination of parabens, triclosan and chlorophenols in water. Acetic anhydride was used as a derivatization reagent, which was placed together with an aliquot of the water sample in sealed vials. After a brief period of pre-equilibrium, the acetylated derivatives were extracted at $100^{\circ} \mathrm{C}$ using a DVB/CAR/PDMS fiber in the HS mode.

Negreira et al. (2009) developed a method for the analysis of salicylate and benzophenone-type UV filters in river water and wastewater samples. Derivatization was done with N-trimethylsilyl-N-methyl trifluoroacetamide just after analyte extraction. Several SPME fibers (PDMS, $100 \mu \mathrm{m}$; PA, $85 \mu \mathrm{m}$; CAR/PDMS, $75 \mu \mathrm{m}$; PDMS/DVB, $65 \mu \mathrm{m}$ ) were tested, and the best results were obtained with the PDMS/DVB mixed fibers, with recoveries between $89 \%$ and $115 \%$ for target compounds (Negreira et al. 2009).

Some authors have proposed electrically enhanced SPME methods as an alternative to improve extraction efficiency. In these methods, fibers function as electrodes, and a potential difference is applied to make charged analytes migrate from the sample to the fiber surface via an electrophoretic process. Fiber can act as a cathode or an anode, and a metal wire is included in the system to function as the opposite pole (Tan et al. 2013). Figure 1 shows a scheme for an electrically enhanced SPME device.

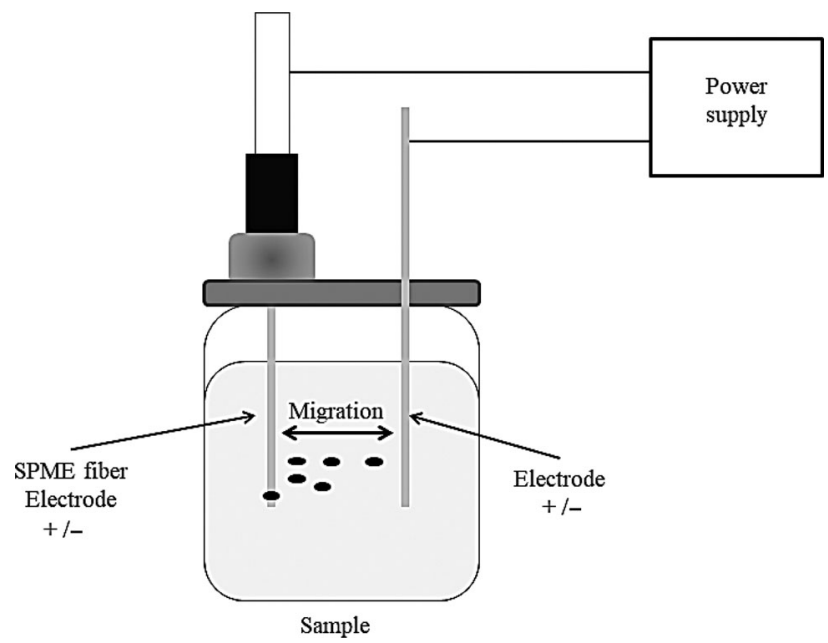

Figure 1: Diagram of an electrically enhanced SPME device.

Tricyclic antidepressants in tap and reservoir water were analyzed using an electrically enhanced SPME method. Different conventional SPME fibers (PA, CAR/PDMS, DVB/CAR/PDMS, and PDMS/DVB) were evaluated, and the best responses were obtained with a PDMS-coated fiber used as a cathode and a platinum wire as an anode. Extraction was carried out for $10 \mathrm{~min}$, and was 10-170 min shorter than other reported methods. Recoveries ranged from $73.9 \%$ to $93.4 \%$ (Xu and Lee 2014 ).

\section{Ionic liquids-based coatings}

At present, ionic liquids (ILs) are among the most frequently used alternative fiber coating materials. ILs are organic salts with melting points lower than $100^{\circ} \mathrm{C}$ that are composed of a bulky organic cation and an organic or inorganic anion. Cohesion forces in these asymmetric ionic compounds are lower than those in common salts, which results in lower melting temperatures (Vičkačkaite and Padarauskas 2012). ILs have a high thermal stability, negligible vapor pressure and null flammability. An important feature of these chemical compounds is that by changing the combination of cations and anions, some properties, such as density, polarity, water miscibility or viscosity, can be adjusted (Ho et al. 2014b). Furthermore, the dual nature of ILs allows them to interact with both polar and non-polar compounds (Poole and Lenca 2015).

One of the most important features in IL-based SPME fiber manufacture is the high viscosity of these liquid salts, which helps obtain better coatings and improve film integrity and homogeneity. The high thermal stability 
of ILs provides more resistant fibers with higher half-lives compared with conventional ones. On the other hand, the liquid nature of the coating facilitates analyte diffusion from bulk matrix samples to SPME fibers, yielding better extraction efficiencies (Aguilera et al. 2010). The hydrophobicity of ILs is another important parameter that must be considered for SPME fiber development, especially for DI applications. ILs containing imidazolium cations combined with different anions have been the most commonly used for SPME fibers (Ho, Canestraro, and Anderson 2011, Ho et al. 2014b).

IL-based SPME fibers are mainly manufactured by immersion-agglutination methods for both fused silica (Amini et al. 2011 and Ho et al. 2012b) and metallic supports (Shi et al. 2016), although sol-gel technologies (Zhou et al. 2012) and chemical modification of the fibers (Zhang et al. 2012b) have also been proposed. Some coating processes include a previous treatment of metallic fibers with acid or a corrosive reagent to achieve better IL penetration and adhesion (Huang et al. 2009). In some cases, an adhesive or binder is combined with ILs to obtain thicker and more resistant coatings (Hsieh et al. 2006 and He et al. 2009). Figure 2 shows a diagram of an immersion-agglutination coating procedure to obtain SPME fibers.

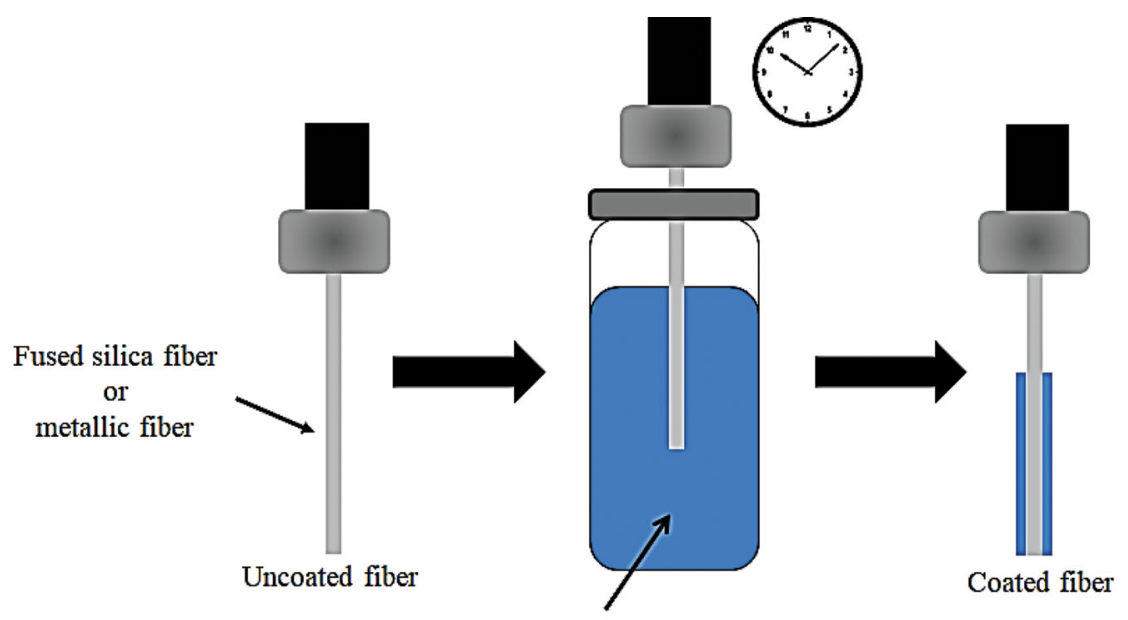

IL o PIL

Figure 2: Immersion-agglutination coating procedure to obtain SPME fibers.

The use of ILs as SPME fiber coatings was first proposed in 2005 by Liu et al. (2005). In this study, fused silica and metallic fibers were coated with 1-octyl-3-methylimidazolium hexafluorophosphate $\left(\left[\mathrm{C}_{8} \mathrm{MIM}\left[\mathrm{PF}_{6}\right]\right)\right.$ and used for HS extraction of benzene, toluene, ethyl benzene and xylene (BTEX) in paints (Liu et al. 2005).

Research using an IL-based SPME for PPCP analysis is scarce. For instance, $\left[\mathrm{C}_{8} \mathrm{MIM}\right]\left[\mathrm{PF}_{6}\right]$-coated stainless steel fibers were applied to alkylphenol determination in river water (Cui et al. 2015). Fibers were prepared by an immersion-agglutination procedure and showed a good performance for DI extraction. Compared with PA fibers $(85 \mu \mathrm{m})$, IL-based fibers showed enrichment factors up to 17 times higher. In addition, the manufacturing process was simple and IL-based fibers were relatively inexpensive.

As previously mentioned, sol-gel technology has emerged as an attractive alternative for SPME fibers coated with ILs, as they provide good thermal resistance (up to $300^{\circ} \mathrm{C}$ ), compatibility with several different solvents, a long half-life and high lot-to-lot reproducibility. In addition, these fibers perform adequately for both HS and DI extraction modes, with good extraction efficiencies up to 200 cycles (Zhou et al. 2012 and Gao et al. 2013). Liu et al. (2010b) reported the fabrication of SPME fibers coated with 1-allyl-3-methylimidazolium hexafluorophosphate ([AMIM] [PF $]$ ) and 1-allyl-3-methylimidazolium bis(trifluoromethanesulfonyl)imide ([AMIM] $\left.\left[\mathrm{N}\left(\mathrm{SO}_{2} \mathrm{CF}_{3}\right)_{2}\right]\right)$ via a sol-gel process using $\gamma$-methacryloxypropyltrimethoxysilane as a bridge. These sol-gel ILbased fibers showed a good performance in DI-SPME of some PPCPs in sewage drainage outlet and lake water samples. Fibers were stable at temperatures up to $320^{\circ} \mathrm{C}$, and resistant to aqueous, acidic, alkaline and chloroformic solutions. Furthermore, an appropriate selectivity for polar phenolic environmental estrogens was observed, with recoveries between $83 \%$ and $104 \%$.

Polymeric ionic liquids (PILs) are polymeric analogs of ILs with similar selectivity and solvation power, but higher viscosity and thermal stability. The PILs most frequently used in SPME fiber coatings are those containing imidazolium cations combined with different anions (Yu, Ho, and Anderson 2013).

PIL-based SPME fibers can use fused silica (González et al. 2013) or metallic supports (Ho et al. 2014a) and have been applied for both DI (López et al. 2010a and Meng and Anderson 2010) and HS (Meng, Pino, and Anderson 2011) extraction procedures. Although a number of methodologies such as UV-initiated in situ copolymerization with ILs (Ho et al. 2012a) or fiber surface chemical modification (Feng et al. 2011) have been used for fiber coating, immersion-agglutination has been the most commonly employed process (Meng and Anderson 2010). PIL-based coatings have improved the thermal, mechanical and chemical resistance of SPME fibers and broadened their applicability to more kinds of samples and a higher number of analytes. 
The first report on the use of PILs as SPME fiber coatings was made in 2008 by Zhao et al. In this work, three PILs bearing the same anion and imidazolium cations were evaluated: 1-vinyl-3-hexylimidazolium bis(trifluoromethylsulfonyl)imide, 1-vinyl-3-dodecylimidazolium and 1-vinyl-3-hexadecylimidazolium. These fibers were prepared by immersing a fused silica fiber in PILs solutions dissolved in acetone, obtaining coatings ranging from 12 to $18 \mu \mathrm{m}$ in thickness. The fibers showed good thermal stability, could be used up to 150 times without any problems and were applied to esters and methyl esters of fatty acid HS analysis in wine samples. Compared with PDMS (7 and $100 \mu \mathrm{m})$ and PA $(75 \mu \mathrm{m})$ commercial SPME fibers, the 1-vinyl-3-hexadecylimidazolium fiber showed a sensitivity that was 325\% higher for methyl nonoate and decanoate (Zhao, Meng, and Anderson 2008).

In a similar way to that with IL-coated SPME fibers, applications that use PIL-based fibers for the PPCP analysis are still limited. For instance, those polymerized from the IL monomer 1-vinyl-3-(10-hydroxydecyl)imidazolium chloride ([VC $\left.{ }_{10} \mathrm{OHIM}\right]$ [Cl]) and IL crosslinker 1,12di(3-vinylbenzylimidazolium) dodecane dichloride $\left(\left[(\mathrm{VBIM})_{2} \mathrm{C}_{12}\right] 2[\mathrm{Cl}]\right.$ ) have been used to determine drugs and phenolic compounds in tap and lake water samples (Yu, Merib, and Anderson 2016) and those polymerized from poly(1-allyl-3-methylimidazolium) bis(trifluoromethylsulfonyl)imide (poly(AM-co-ED)) have been used to extract alkylphenols from sludge, tap and river water (Mei et al. 2015b). In addition, PILs based on alkyl methacrylate-ester, divinylbenzene and vinylbenzyl trimethylammonium chloride (poly(AMADVB-VBTA)) have been synthesized for the extraction of non-steroidal anti-inflammatory drugs (Liu et al. 2015).

Another approach to broaden PIL-based SPME fiber applications has been to use functionalized PILs. For instance, López et al. (2010b) produced an SPME fiber coated with poly(1(4-vinylbenzyl)-3-hexadecylimidazolium bis[(trifluoromethyl)sulfonyl]imide $\left(\operatorname{poly}\left(\operatorname{VBHDIm}^{+} \mathrm{NTf}_{2}{ }^{-}\right)\right.$), a PIL including benzyl groups in its structure, and gave it a more hydrophobic character. The obtained fiber was used for DI extraction of some alkylphenols and parabens in water samples and presented a lifetime of 70 cycles. The performance of the benzyl-functionalized PIL-coated SPME fiber was compared with PA (85 $\mu \mathrm{m})$ and PDMS $(30 \mu \mathrm{m})$ commercial fibers and, despite having a lower coating thickness $(12 \mu \mathrm{m})$, provided better results for the analytes included in the study (López et al. 2010b).

Monolithic SPME fibers are very thin rods that can be prepared with different materials such as polymers or graphene. Monolithic fibers have important advantages: their preparation is simple, they are flexible and solvent resistant and they show higher mass transference rates than conventional fibers. Due to their physical and chemical characteristics, monolithic fibers can be used for DI-SPME extractions (Mei, Huang, and Yuan 2014). Multiple monolithic fiber SPME (MMF-SPME) is an alternative approach based on the use of a device that contains several monolithic fibers bound together. Fibers in the device have some space between them, which allows for sample convection and enhanced mass transfer (Mei et al. 2015a). Recently, PILs have been used as MMF-SPME fiber coating. For example, monolithic fibers coated with poly(1-allyl-3-methylimidazolium) bis(trifluoromethylsulfonyl)imide co-polymerized with ethylene dimethacrylate have been used for sex hormone steroid analysis in tap and lake water. A good performance of this PIL-MMF-SPME method was observed with recoveries for target analytes between $75 \%$ and $166 \%$, a lifetime higher than 200 cycles and analysis times (Liao et al. 2016).

PILs have also been used with other extraction materials for coating monolithic fibers. Sun et al. (2016) developed a fiber coated with a PIL-doped graphene oxide (GO). The monomers used were 1-(3-aminopropyl)-3-(4-vinylbenzyl)imidazolium 4-styrenesulfonate ([(APIM)(VB)] [SS]) and 1,6di-(3-vinylimidazolium)hexane bis(hexafluorophosphate) $\left(\left[\mathrm{C}_{6}(\mathrm{VIM})_{2}{ }^{2+}\right] 2\left[\mathrm{PF}_{6}\right]\right)$ as a crosslinking agent. The prepared SPME fiber was applied to phenolic compound analysis in river water and groundwater of an industrial park, with recoveries between $79 \%$ and $113 \%$ for all analytes (Sun et al. 2016). Table 3 presents a selection of SPME methods for PCPP analysis using fibers with IL and PIL coatings. 


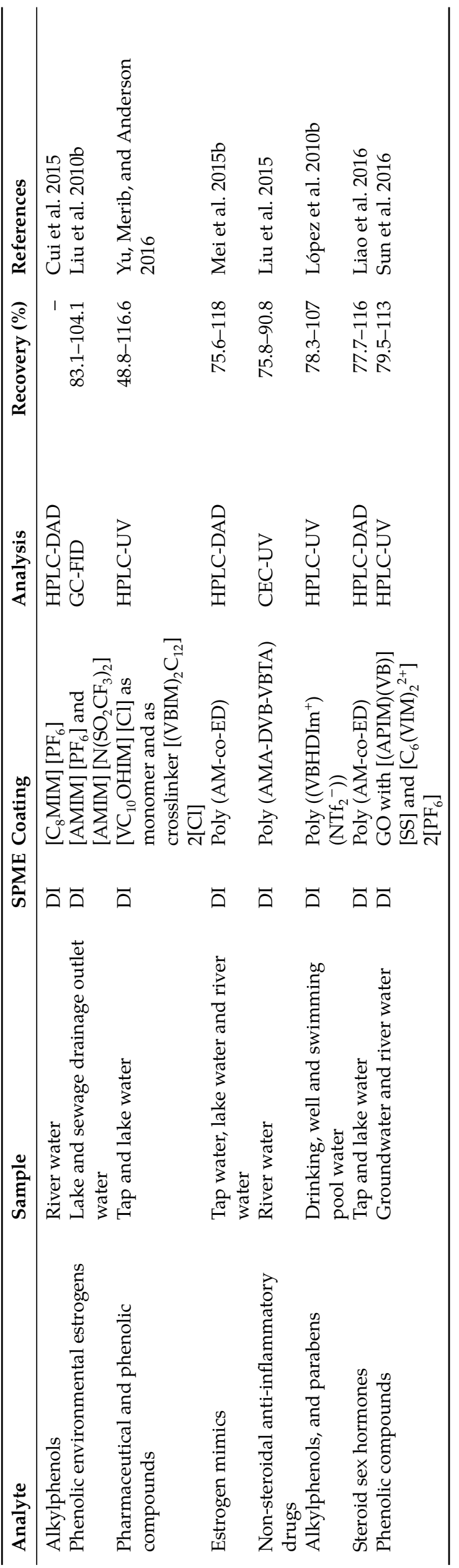




\section{Molecularly imprinted polymer coatings}

Molecularly imprinted polymers (MIPs) are synthetic polymers that have recently shown great utility in many fields of analytical chemistry. MIPs are obtained by polymerization of a monomer with a crosslinking agent in the presence of the selected template molecule. After polymerization, the template is removed from the polymeric network, leaving binding sites that are complimentary in size, shape and chemical functionality to the template molecule, and thereby producing a polymer capable to selectively trap target analytes (Zhang et al. 2013).

MIPs are usually prepared trough free radical polymerization at temperatures lower than $80^{\circ} \mathrm{C}$ and at atmospheric pressure. Template molecules direct the organization of monomer functional groups and define the properties of binding sites. Analytes such as drugs, amino acids, carbohydrates, proteins, nucleotides, hormones, pesticides and some coenzymes are among the common templates used for MIPs, while the most commonly used monomers are 4-vinyl pyridine, 2-vinylpyridine, acrylamide, methacrylic acid, 4-vinylpyridine, trifluoromethyl acrylic acid, 2-acrylamido-2-methyl-1-propanesulfonic acid and 2-hydroxyethyl methacrylate (Turiel and Martin 2009). Crosslinking agents control the morphology of the polymeric matrix, stabilize the imprinted binding site, give MIPs mechanical stability and influence the size of the nanoparticulate system of the obtained MIP. Ethylene glycol dimethacrylate, trimethylolpropane trimethacrylate, pentaerythritol triacrylate and divinylbenzene are among the most important crosslinking agents employed for MIPs. Finally, solvents in MIP synthesis also play an important role, as they are responsible for maintaining all components in only one phase and for polymer pore formation (porogen). The common solvents for MIP synthesis are chloroform, dichloromethane and acetonitrile (Vasapollo et al. 2011). Figure 3 presents a scheme of the fabrication basic principle of MIP and an example of an SPME fiber coating process.

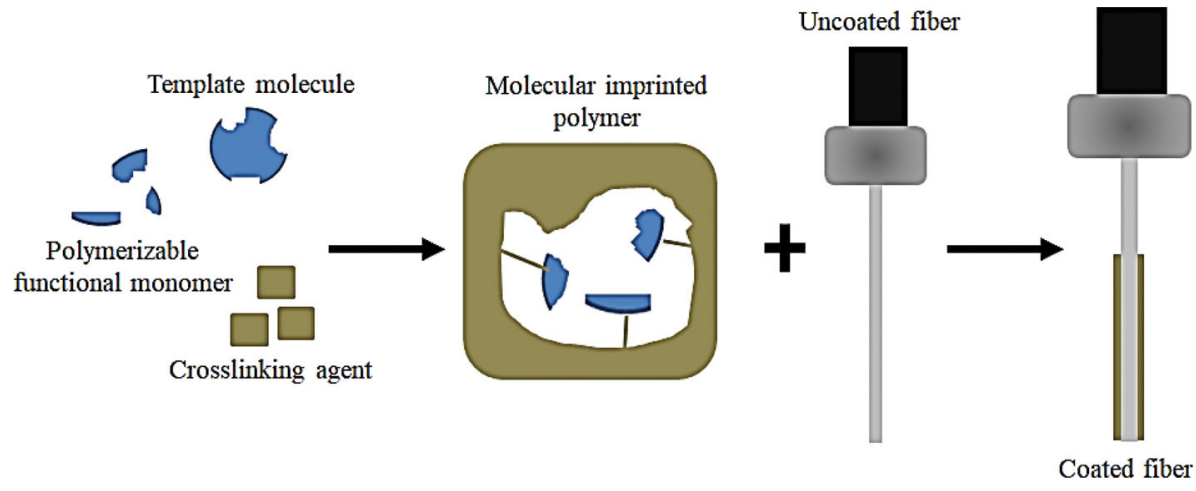

Figure 3: Fabrication procedure for MIPs and coating of an SPME fiber.

MIPs have been used as coatings for SPME fused silica or metallic fibers, mainly through in situ polymerization (Hu et al. 2010). These kinds of fibers are considered inexpensive, highly selective and highly reproducible (Sarafraz and Razavi 2015). The first report on MIP-coated SPME fibers was by Koster et al. (2001) for the extraction of clenbuterol and five analog substances. The authors of these studies produced a $75-\mu \mathrm{m}$-thick methacrylate polymer using clenbuterol as a template molecule (Koster et al. 2001).

Due to their high solvent resistance and wide $\mathrm{pH}$ stability, among other interesting features, MIP-based SPME fibers can be used for DI extractions and thus are a very attractive alternative for PPCP analysis. For example, the anti-HIV drug abacavir was determined in surface and residual waters using an SPME fiber coated with an acrylic acid-based MIP (Terzopoulou et al. 2016). This SPME fiber was prepared by radical polymerization with abacavir as a template, ethylene glycol dimethacrylate as a crosslinking agent and dimethylformamide as porogen. A good recognition capability for abacavir was observed in real sample analysis, with extraction efficiencies ranging from $88 \%$ to $99 \%$, and no matrix effects.

Recently, Díaz et al. (2016) developed a fused silica fiber coated with an MIP prepared in situ using a bifunctional monomer, N,O-bismethacryloyl ethanolamine, that works as both a monomer and a crosslinking agent. The template molecule was benzylparaben, acetonitrile was employed as porogen solvent and polymerization was carried out under UV irradiation. These MIP-coated fibers were evaluated in SPME for the PPCP group of parabens present in spiked agricultural soil and sea sediments. A good performance was observed, with recoveries between 78\% and 109\% and relative standard deviations lower than 15\% (Díaz et al. 2016).

In order to increase the mechanical stability of MIP-based fibers, monolithic fibers have been developed and applied to the extraction of diacetylmorphine and analogous compounds in aqueous solution using diacetylmorphine as a template molecule (Djozan and Baheri 2007). For PPCPs, a bisphenol A-imprinted MIP-based fiber was developed for the analysis of bisphenol A and its analogs, diethylstilbestrol and hexestrol, in tap water 
and sewage. Monolithic fibers were prepared using a microwave-assisted in situ polymerization process in a flexible capillary mold with bisphenol A as a template molecule. Methacrylic acid, ethylene glycol dimethacrylate and acetonitrile were the monomer, crosslinking agent and solvent, respectively. MIP-based monolithic fibers showed satisfactory performance, with recoveries between $83 \%$ and $104 \%$ for target analytes in real samples and fiber-to-fiber relative standard deviations (RSDs) between 6.6\% and 9.5\% (Xu et al. 2013b).

\section{Carbon-based coating materials}

Materials based in allotropic carbon forms have been widely employed in sample preparation techniques. Some of these materials are regarded as nanomaterial and possess a high superficial area, which provides a high extraction capacity. Carbon nanotubes (CNTs), graphene, GO and fullerenes are among the most commonly used (Souza, Risticevic, and Pawliszyn 2013).

All carbon-based materials present a basic structure composite by hexatomic rings with $\mathrm{sp}^{2}$ hybridized carbons that give them similar physical and chemical properties. These compounds interact with non-polar molecules, and to a lesser extent, with polar and some ionic compounds through non-covalent interactions such as hydrogen bonds, $\pi-\pi$ interactions, electrostatic forces, Van der Waals forces and hydrophobic interactions (Ghaemi, Amiri, and Yunus 2014). Figure 4 shows a schematic representation of SPME fibers coated with different allotropic carbon forms.

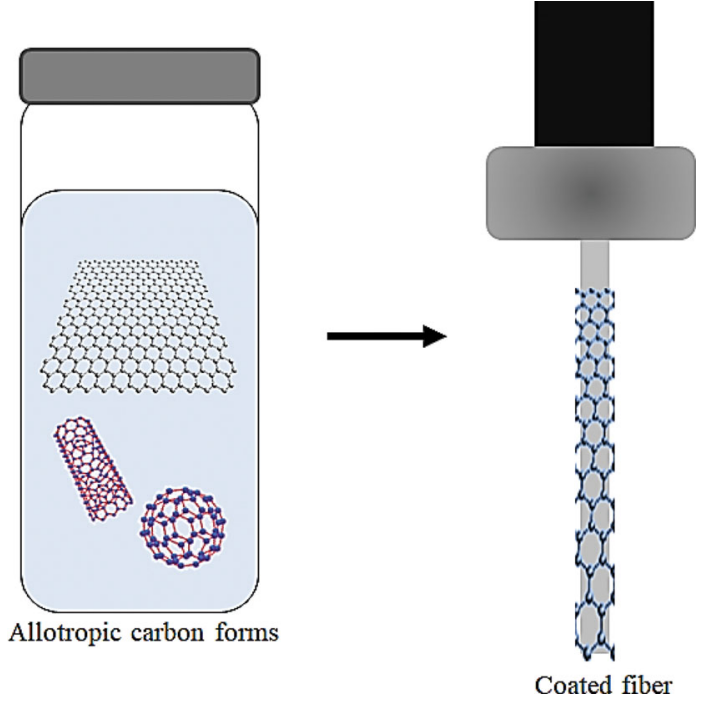

Figure 4: Schematic representation of SPME fibers coated with different allotropic carbon forms.

Graphene is a material formed by pure carbon with atoms arranged in a single layer of regular hexagonal rings, similar to graphite and it has been used as SPME fiber coating due to its high surface area and mechanical, chemical and thermal stability. In addition, graphene can be functionalized, which provides greater versatility for the extraction of a wide variety of compounds. The best example of this is GO (Mehdinia and Aziz 2013b).

The first application of graphene for SPME fibers was reported for pyrethroid determination in water samples (Chen et al. 2010). The preparation process included immersion of a stainless steel wire into a grapheneadhesive suspension, resulting in a coating film with a thickness of about $6-8 \mu \mathrm{m}$. This coating showed good thermal and mechanical resistance with an average half-life of 250 extraction cycles. Due to their porous surface and strong affinity for target analytes, graphene-based fibers yielded extraction efficiencies 1.5 times higher than PDMS $(100 \mu \mathrm{m})$ and PDMS/DVB $(65 \mu \mathrm{m})$ commercial fibers.

Graphene-based SPME fibers prepared via sol-gel procedures usually support high temperatures $\left(>350^{\circ} \mathrm{C}\right)$, while chemical bonding methodologies give them greater resistance to organic solvents, acids and bases (Liu, Shi, and Jiang 2012a).

Regarding the PPCP analysis from environmental samples, a graphene-based SPME fiber was prepared via sol-gel for extraction of some UV filters (benzophenone, octyl salicylate, homosalate, 3-(4-methylbenzylidene) camphor, 2-hydroxy-4-methoxybenzophenone) commonly used in cosmetics, sunscreens and personal care products from river water. Extractions using these fibers were made in the DI mode, and an in-fiber derivatization step was included to allow analyte determination by GC-MS. Enrichment factors from 1080 to 10,155 were obtained for target analytes, and compared with PDMS $(100 \mu \mathrm{m})$, PDMS/DVB $(65 \mu \mathrm{m})$ and PA $(85 \mu \mathrm{m})$ 
commercial fibers, graphene-based fibers provided higher efficiency for the less polar analytes (Zhang and Lee 2012a).

On the other hand, Li et al. (2016) developed a fiber by covering a stainless steel fiber with aminofunctionalized graphene powder using a silicone adhesive; the obtained coating presented a thickness of about $30 \mu \mathrm{m}$. Synthetic musks were extracted by DI from tap and river water. Graphene coating provided a half-life higher than 200 cycles, was stable up to $290^{\circ} \mathrm{C}$ and yielded extraction efficiencies between $82 \%$ and $112 \%$, which were better than those obtained using PDMS $(100 \mu \mathrm{m})$, PDMS /DVB $(65 \mu \mathrm{m})$ and PA $(85 \mu \mathrm{m})$ commercial fibers (Li et al. 2016).

CNTs can be classified in single-walled nanotubes (SWNTs) and multi-walled nanotubes (MWNTs); SWNTs are rods with a single sealed graphene layer, while MWNTs are formed by several concentric SWNTs bounded by Van der Waals forces. Typically, diameters vary from 1 and $10 \mathrm{~nm}$ for SWNTs and from 5 to a few $100 \mathrm{~nm}$ for MWNTs (Mehdinia and Aziz 2013b).

Both SWNTs and MWNTs present unique electronic, electric, thermal and mechanical properties. Besides, these materials exhibit hydrogen bonding, $\pi-\pi$, dispersion and hydrophobic interactions with volatile and semivolatile organic compounds and can present other kinds of interactions because they can be functionalized $(\mathrm{Xu}$ et al. 2013a).

As SPME fiber coatings, CNTs were first introduced by Wang et al. (2006). For PPCP analysis, SWNTs have been used as fiber coatings for extraction of some endocrine disruptors, such as bisphenol A, estrone, 17ethinylestradiol and octylphenol, from tap and seawater. A thin platinum wire was used for the electrophoretic deposition of SWNTs, and the obtained fiber provided a half-life of 120 cycles (Ma, Li, and Yuan 2011). On the other hand, MWNTs functionalized with polyethylene glycol were used for coating a fused silica fiber via a sol-gel process. This fiber was applied to ibuprofen, naproxen and diclofenac extraction from water samples; it was stable at temperatures up to $320^{\circ} \mathrm{C}$ and could be used for at least 150 extraction cycles (Sarafraz et al. 2012).

Carbon nanospheres (CNs) constitute another group of interesting carbon-based materials. CNs are highly curved graphite structures that have a well-developed crystalline structure, high electrical conductivity, good thermal stability and resistance to oxidation. The internal diameters of CNs range from $1 \mu \mathrm{m}$ to $2 \mathrm{~nm}$ (Zhang et al. 2014). CNs are also called carbon nanocapsules, especially when they contain metal. The use of CNs has been scarce, mainly due to their high cost and the heterogeneous products obtained during synthesis that are difficult to purify (Nieto et al. 2011). The first report dealing with the use of CNs in fiber coatings was recently made by Zheng et al. (2015), who coated a stainless steel fiber using a sol-gel methodology. The fiber was applied to the analysis of heterocyclic aromatic hydrocarbons and organochlorine pesticides in river water and wastewater, obtaining recoveries between $73 \%$ and $120 \%$. Fibers were stable up to $350^{\circ} \mathrm{C}$ and at a pH range of 1-13 (Zheng et al. 2015).

A CN-coated SPME fiber was developed for the DI-SPME analysis of octylphenol and nonylphenol in tap, rain, drinking and wastewater. The preparation process involved the use of stainless steel treated with hydrochloric acid that was covered with a silicone adhesive to fix carboxylic-functionalized CNs. A CN coating of around $30 \mu \mathrm{m}$ was obtained and showed good thermal stability $\left(>330^{\circ} \mathrm{C}\right)$. Analytes recoveries ranged from $80 \%$ to $102 \%$, and detection limits using this fiber were lower than PDMS (100 $\mu \mathrm{m})$, PA $(85 \mu \mathrm{m})$, PDMS/DVB $(65 \mu \mathrm{m}), \mathrm{CW} / \mathrm{DVB}(70 \mu \mathrm{m})$ and PIL fibers (Gong et al. 2015).

\section{Other coating materials}

The good thermal, mechanical and chemical stability exhibited by some metals and oxides has driven the use of these inorganic materials in SPME fibers. These compounds can be employed in different configurations, such as nanoparticles, sheets and layers. The good selectivity of these materials can be attributed to the electronic structures of the metals and oxides involved, and hydrophobic interactions, electrostatic attractions or covalent bond formation may be present (Aziz and Mehdinia 2014).

For PPCP analysis, a Ti-TiO $-\mathrm{ZrO}_{2}$ fiber was prepared by chemical oxidation of a titanium wire and further electroctrodeposition of $\mathrm{ZrO}_{2}$ nanoparticles. This fiber was applied to UV filters determination in river water and wastewater. 2-Hydroxy-4-methoxybenzophenone, 2-ethylhexyl-4-methoxycinnamate, 2ethylhexyl-4-(N,N-dimethylamino) benzoate and ethylhexyl salicylate were extracted by DI of the $\mathrm{Ti}-\mathrm{TiO}_{2}-\mathrm{ZrO}_{2}$ fiber into the samples with good performance in more than 250 extraction cycles (Li et al. 2014a). Gold nanoparticles ( $\mathrm{C}_{8}$-S-AuNPs /SS) have also been used for SPME fiber coating and applied to UV filters and phthalate ester extraction from river and rain water and for samples from sewage treatment plants (Yang et al. 2014).

Metal oxide nanosheets have also been employed for SPME fiber fabrication. Nanosheets are twodimensional structures that range in thickness from 1 to $100 \mathrm{~nm}$ and have a high surface area, good electrical properties and high durability (Coleman et al. 2011). An SPME fiber coated with $\mathrm{TiO}_{2}$ nanosheets has been 
proposed for DI SPME of phthalate and UV filter determination in river and residual waters. Nanosheets were deposited by anodization of a titanium wire, yielding a coating with a thickness of $0.08 \mu \mathrm{m}$ that could resist at least 250 extraction cycles ( $\mathrm{Li}$ et al. 2014b). These compounds have also been extracted using an SPME fiber coated by electrodeposition of $\mathrm{Zn}-\mathrm{ZnO}$ nanosheets on a worn wire fiber (Song et al. 2015).

Metal-organic frameworks (MOFs) are porous materials formed by a wide variety of metal ion clusters connected by organic ligands. These materials have high superficial areas, and both their pore size and thermal stability can be adjusted (Li, Sculley, and Zhou 2012 and Tian et al. 2013).

The coordination complex formed by $\mathrm{Cu}(\mathrm{II})$ and benzene-1,3,5-tricarboxylic acid, called MOF-199, was the first MOF employed as coating for SPME fibers. In situ immobilization was made on a steel wire worn through a hydrothermal growth method, obtaining a coating with a thickness of approximately $40 \mu \mathrm{m}$ that was stable at temperatures up to $289^{\circ} \mathrm{C}$. This SPME fiber was used for the extraction of benzene homologues in air samples (Cui et al. 2009). Reports of MOFs used for PPCPs have also been published. An ethylene dimethacrylate and butyl methacrylate polymeric monolithic fiber containing an aluminum based-MOF (MIL-53) was successfully used for SPME of a group of penicillins (penicillin G, penicillin V, oxacillin, cloxacillin, dicloxacillin, and nafcillin) in water river samples (Lirio et al. 2016).

Conducting polymers (CPs) such as polypyrrole, polythiophene, polyaniline and its derivatives have been used as SPME fiber coatings. CPs are rigid molecules that produce fibers with good hardness and durability and, because they have a rough and porous surface, show good adsorption capacity (Bagheri, Ayazi, and Naderi 2013). CP-based fibers commonly employ metal wires as support, and coating is carried out by electrodeposition or in situ polymerization procedures. The thickness of the coatings can be of hundreds of micrometers. As these materials show abundant hydrophobic interactions, they constitute an attractive alternative to non-polar adsorbents (Aziz and Mehdinia 2013).

PPCPs have been analyzed using CP-coated SPME fibers. Liu et al. (2012b) developed an electrochemically enhanced SPME method using a platinum fiber coated with a mixture of CNs and polypyrrole molecularly imprinted (MIPPy / MWCNTs) for fluoroquinolones determination in water and soil samples. Adequate results were obtained with good selectivity for target analytes, as well as higher extraction efficiencies than conventional SPME fibers and a lifetime of more than 50 extraction cycles (Liu et al. 2012b). Figure 5 shows schematic representations of some SPME fibers with coatings based on conductive polymers and MOFs.

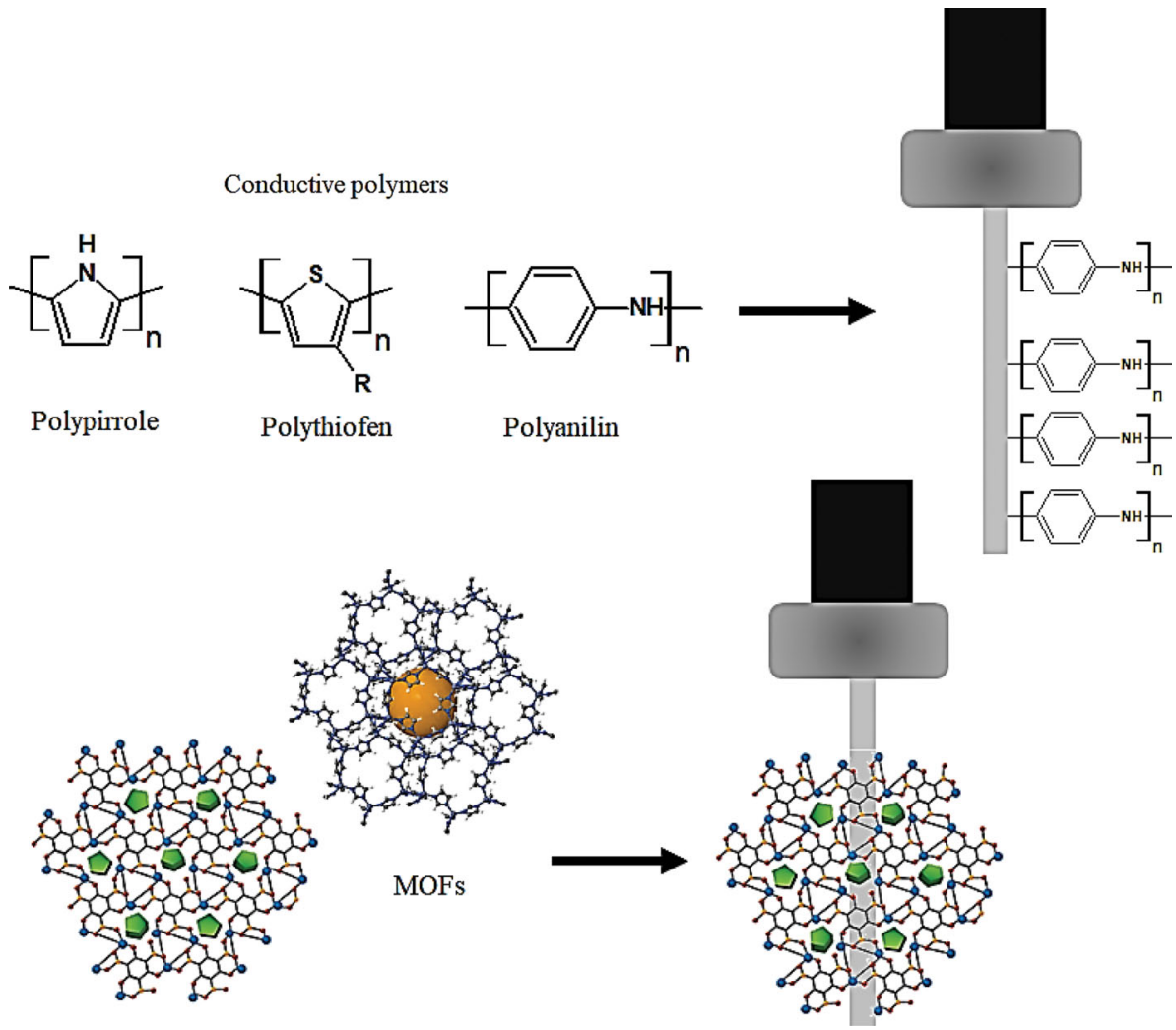

Figure 5: Schematic representation of SPME fibers coated with conductive polymers and MOFs.

On the other hand, recently, basalt fibers coated in situ with a low cost and environmentally friendly polyaniline polymer were prepared by a hydrothermal growth method. An in-tube SPME device was obtained by filling a $20-\mathrm{cm}$ polyetheretherketone (PEEK) tube with the polyaniline-coated basalt fibers. An online SPME-HPLC system was obtained connecting extraction devices to a six-port injection valve. Applicability 
of the in-tube SPME device developed was demonstrated by extracting three ultraviolet filters, including 2hydroxy-4-methoxybenzophenone, phenyl salicylate and 2,4-dihydroxybenzophenone. Extraction and desorption conditions were established and enrichment factors between 1323 and 1555 were obtained, with detection limits from 0.02 to $0.05 \mu \mathrm{g} \mathrm{l^{-1 }}$. Extraction devices were successfully applied to the determination of the ultraviolet filters in environmental water samples and sewage water, with recoveries from $97 \%$ to $114 \%$ for river water and from $82 \%$ to $115 \%$ for sewage water (Bu et al. 2017).

Inmunoaffinity SPME has been developed as a new alternative to conventional SPME. Antibodies specific for target analytes are immobilized on fused silica fibers or stainless steel wires, previously coated with porous silica particles. In this way, highly selective, rugged and robust SPME fibers are obtained (Breton et al. 2010 and Lord et al. 2016). In recent report by Wang et al. (2017), immunoaffinity SPME rods were used for extraction of diethylstilbestrol, hexestrol and dienestrol followed by Ultra-high performance liquid chromatography tandem mass spectrometry (UHPLC-MS/MS) analysis. Immunoaffinity SPME rods were prepared by covalent linking of an antidiethylstilbestrol monoclonal antibody to a stainless steel rods coated with carbonyl-functionalized porous silicate particles. SPME devices were obtained with three coated stainless steel rods bundled together. Detection limits for target estrogens obtained were between 0.05 and $0.15 \mathrm{ng} \mathrm{ml}^{-1}$. Immunoaffinity SPME fibers showed a stable extraction performance for at least ten sequential analysis of tap, pond and river water, with average recoveries from $34.2 \%$ to $62.7 \%$ for the three analytes (Wang et al. 2017). Table 4 presents a selection of SPME methods for PCPP analysis using fibers with other alternative coating materials. 


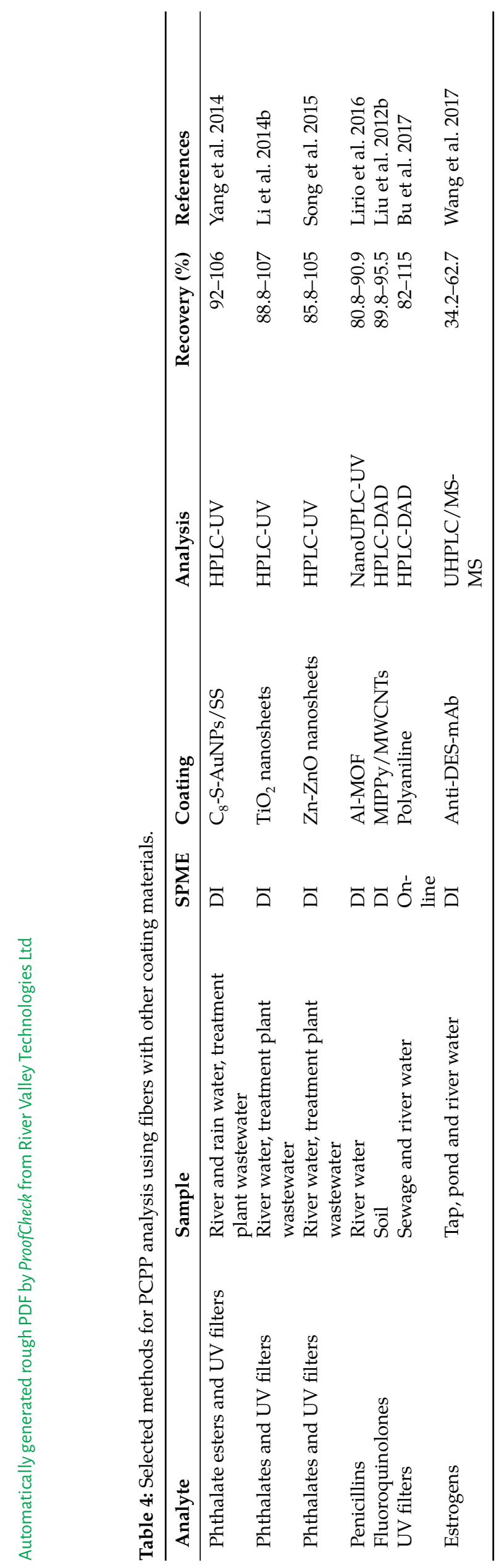




\section{Conclusions}

Because of matrix complexity and the low concentration levels that analytes usually present, the analysis of environmental samples is one of the areas in analytical chemistry in which the use of sample preparation techniques is most frequently required.

Current trends in the development of analytical methods have focused on making them environmental friendly, fast and easily automatable, giving rise to a new generation of sample microextraction techniques with SPME occupying a distinguished place, especially in environmental analysis.

Understanding SPME principles has resulted in the evolution of conventional fiber coatings, allowing the emergence of new materials that show improved chemical and mechanical resistance, as well as improved selectivity and extraction efficiency. Furthermore, fibers coated with these new materials have broadened SPME applications for both matrix samples and analytes.

PPCPs are chemical compounds that are present in a great number of daily use products, and due to their physical and chemical properties, can easily reach different ecosystems. Despite the fact that PPCPs are widely used all over the world, the presence of these compounds in the environment is not regulated.

Currently, SPME is a well-recognized technique in environmental analysis, but its applications for PPCP determination in environmental samples are still scarce. Commercially available fibers have been broadly applied and consolidated in the analysis of these compounds, and the advances made in the development of new coatings with different materials have exceeded the performance of commercial SPME fibers. Nevertheless, further research on the identification and quantification of these compounds is needed.

\section{Acknowledgments}

The authors acknowledge the support provided by SEP-CONACYT Ciencia Básica 2015 (256711), PRODEP (UANL-PTC-935) and UANL-PAICYT 2015 funds (CE340-15).

\section{Funding}

O.J. Portillo-Castillo acknowledges support from CONACYT grant (247590), Consejo Nacional de Ciencia y Tecnología, Funder Id: 10.13039/501100003141.

\section{References}

Aguilera, H. E.; Lucena, R.; Cardenas, S.; Valcarcel, M. The roles of ionic liquids in sorptive microextraction techniques. Trends Anal. Chem. 2010, $29,602-616$.

Al-Qaim, F. F.; Abdullah, M. P.; Othmanm M. R.; Latip, J.; Zakaria, Z. Multi-residue analytical methodology-based liquid chromatographytime-of-flight-mass spectrometry for the analysis of pharmaceutical residues in surface water and effluents from sewage treatment plants and hospitals. J. Chromatogr. A 2014, 1345, 139-153.

Amini, R.; Rouhollahi, A.; Adibi, M.; Mehdinia, A. A new disposable ionic liquid based coating for headspace solid-phase microextraction of methyl tert-butyl ether in a gasoline sample followed by gas chromatography-flame ionization detection. Talanta 2011, 84, 1-6.

Aresta, A.; Bianchi, D.; Calvano, C. D.; Zambonin, C. G. Solid phase microextraction-liquid chromatography (SPME-LC) determination of chloramphenicol in urine and environmental water samples. J. Pharm. Biomed. Anal. 2010, 53, 440-444.

Arthur, C. L.; Pawliszyn, J. Solid phase microextraction with thermal desorption using fused silica optical fibers. Anal. Chem. 1990, 62, 2145-2148.

Aziz, Z. M. O.; Mehdinia, A. Electrochemically prepared solid-phase microextraction coatings-A review. Anal. Chim. Acta 2013, 781, 1-13.

Aziz, Z. M. O.; Mehdinia, A. A review on procedures for the preparation of coatings for solid phase microextraction. Microchim. Acta 2014, 181, 1169-1190.

Aznar, R.; Albero, B.; Sanchez, B. C.; Miguel, E.; Martin, G. I.; Tadeo, J. L. Simultaneous determination of multiclass emerging contaminants in aquatic plants by ultrasound-assisted matrix solid-phase dispersion and CC-MS. Environ. Sci. Pollut. Res. 2016, 24, 7911-7920.

Bagheri, H.; Ayazi, Z.; Naderi, M. Conductive polymer-based microextraction methods: a review. Anal. Chim. Acta 2013, 767, 1-13.

Basaglia, G.; Pasti, L.; Pietrogrande, M. C. Multi-residual CC-MS determination of personal care products in waters using solid-phase microextraction. Anal. Bioanal. Chem. 2011, 399, 2257-2265.

Basaglia, G.; Pietrogrande, M. C. Optimization of a SPME/CC/MS method for the simultaneous determination of pharmaceuticals and personal care products in waters. Chromatographia 2012, 75, 361-370.

Birch, G. F.; Drage, D. S.; Thompson, K.; Eaglesham, G.; Mueller ], F. Emerging contaminants (pharmaceuticals, personal care products, a food additive and pesticides) in waters of Sydney estuary, Australia. Mar. Pollut. Bull. 2015, 97, 56-66. 
Bratkowska, D.; Marce, R. M.; Cormack, P. A. G; Borrull, F.; Fontanals, N. Development and application of a polar coating for stir bar sorptive extraction of emerging pollutants from environmental water samples. Anal. Chim. Acta 2011, 706, 135-142.

Breton, F.; Monton, M. R. N.; Mullett, W. M.; Pawliszyn. Silicate-entrapped porous coatings for preparing high-efficiency solid-phase microextraction sorbents. J. Anal. Chim. Acta 2010, 669, 39-44.

Bu, Q.; Wang, B.; Huang, J.; Deng, S.; Yu, G. Pharmaceuticals and personal care products in the aquatic environment in China: a review. J. Hazard. Mater. 2013, 262, 189-211.

$\mathrm{Bu}$, Y.; Feng, J.; Wang, X.; Tian, Y.; Sun, M.; Luo, C. In situ hydrothermal growth of polyaniline coating for in-tube solid-phase microextraction towards ultraviolet filters in environmental water samples. J. Chromatogr. A 2017, 1483, 48-55.

Buchberger, W. W. Current approaches to trace analysis of pharmaceuticals and personal care products in the environment. J. Chromatogr. A 2011, 1218, 603-618.

Celano, R.; Piccinelli, A. L.; Campone, L.; Rastrelli, L. Ultra-preconcentration and determination of selected pharmaceutical and personal care products in different water matrices by solid-phase extraction combined with dispersive liquid-liquid microextraction prior to ultra high pressure liquid chromatography tandem mass spectrometry analysis. J. Chromatogr. A 2014, 1355, 26-35.

Chen, J.; Zou, J.; Zeng, J.; Song, X.; Ji, J.; Wang, V.; Ha, J.; Chen, X. Preparation and evaluation of graphene-coated solid-phase microextraction fiber. Anal. Chim. Acta 2010, 678, 44-49.

Chopra, S.; Lima, G. P. C. F.; Dhandapani, R.; Snow, N. H. Analysis of steroids using solid phase microextraction-gas chromatography-mass spectrometry-mass spectrometry (SPME-CC-MS-MS). Scientia Chromatographica 2014, 6, 105-116.

Coleman, J. N.; Lotya, M.; O’Neill, A.; Bergin, S. D.; King, P. J.; Khan, U.; Young, K.; Gaucher, A.; De S.; Smith, R. J.; Shvets, I. V.; Arora, S. K.; Stanton, G.; Kim, H.-Y.; Lee, K.; Kim, G. T.; Duesberg, G. S.; Hallam, T.; Boland, J. J.; Wang, J.J.; Donegan, J. F.; Grunlan, J.C.; Moriarty, G.; Shmeliov, A.; Nicholls, R. J.; Perkins, J. M.; Grieveson, E. M.; Theuwissen, K.; McComb, D. W.; Nellist, P. D.; Nicolosi, V. Two-dimensional nanosheets produced by liquid exfoliation of layered materials. Science 2011, 331, 568-571.

Cui, X. Y.; Gu, Z. Y.; Jiang, D. Q.; Li, Y.; Wang, H. F.; Yan, X. P. In situ hydrothermal growth of metal-organic framework 199 films on stainless steel fibers for solid-phase microextraction of gaseous benzene homologues. Anal. Chem. 2009, 81, 9771-9777.

Cui, M.; Qiu, J.; Li, Z.; He, M.; Jin, M.; Kim, J.; Quinto, M.; Li, D. An etched stainless steel wire/ionic liquid-solid phase microextraction technique for the determination of alkylphenols in river water. Talanta 2015, 132, 564-571.

Díaz, A. M.; Smith, S. T.; Spivak, D. A.; Martín, E. A. Preparation of molecularly imprinted polymeric fibers using a single bifunctional monomer for the solid-phase microextraction of parabens from environmental solid samples. J. Sep. Sci. 2016, 39, 552-558.

Djozan, D.; Baheri, T. Preparation and evaluation of solid-phase microextraction fibers based on monolithic molecularly imprinted polymers for selective extraction of diacetylmorphine and analogous compounds. J. Chromatogr. A 2007, 1166, 16-23.

Ellis, J. B. Pharmaceutical and personal care products (PPCPs) in urban receiving waters. Environ. Pollut. 2006, 144, 184-189.

EPA Method 198. 2007. https://www.epa.gov/sites/production/files/2015-10/documents/method_1698_2007.pdf (accessed August 2017).

EPA Method 1694. 2007. https:/www.epa.gov/sites/production/files/2015-10/documents/method_1694_2007.pdf (accessed August 2017).

Feitosa, L. C. P. C.; Barletta, J. Y.; Domingues, N. C. E.; Santos, N. A. J.; Von Wolff, M. A; Reganhan, C. C. M.; Aragão, U. C.; Lancas, F. M. Optimization of in situ derivatization SPME by experimental design for CC-MS multiresidue analysis of pharmaceutical drugs in wastewater. J. Sep. Sci. 2011, 34, 436-445.

Feng, J.; Sun, M.; Xu, L.; Li, J.; Liu, X.; jiang, S. Preparation of a polymeric ionic liquid-coated solid-phase microextraction fiber by surface radical chain-transfer polymerization with stainless steel wire as support. J. Chromatogr. A 2011, 1218, 7758-7764.

Gao, Z.; Deng, Y.; Hu, X.; Yang, S.; Sun, C.; He, H. Determination of organophosphate esters in water samples using anionic liquid-based solgel fiber for headspace solid-phase microextraction coupled to gas chromatography-flame photometric detector. J. Chromatogr. A 2013, $1300,141-150$.

Chaemi, F.; Amiri, A.; Yunus, R. Methods for coating solid-phase microextraction fibers with carbon nanotubes. Trends Anal. Chem. 2014, 59, 133-143.

Gil, G. M. D.; Cañada, C. F.; Culzoni, M. J.; Vera, C. L.; Siano, G. G.; Goicoechea, H.C.; Martinez, G. M. Chemometric tools improving the determination of anti-inflammatory and antiepileptic drugs in river and wastewater by solid-phase microextraction and liquid chromatography diode array detection. J. Chromatogr. A 2009, 1216, 5489-5496.

Gilart, N.; Miralles, N.; Marce, R. M.; Borrull, F.; Fontanals, N. Novel coatings for stir bar sorptive extraction to determine pharmaceuticals and personal care products in environmental waters by liquid chromatography and tandem mass spectrometry. Anal. Chim. Acta 2013, 774 $51-60$.

Gracia, L. E.; Martínez, M.; Sancho, J. V.; Peñuela, G.; Hernandez, F. Multi-class determination of personal care products and pharmaceuticals in environmental and wastewater samples by ultra-high performance liquid-chromatography-tandem mass spectrometry. Talanta $\mathbf{2 0 1 2}$, 99, 1011-1023.

Codayol, A.; Besalu, E.; Antico, E.; Sanchez, J. M. Monitoring of sixteen fragrance allergens and two polycyclic musks in wastewater treatment plants by solid phase microextraction coupled to gas chromatography. Chemosphere 2015, 119, 363-370.

Cong, S. X.; Wang, X.; Li, L.; Wang, M. L.; Zhao, R. S. Enrichment and determination of octylphenol and nonylphenol in environmental water samples by solid-phase microextraction with carboxylated carbon nano-spheres coating prior to gas chromatography-mass spectrometry. Anal. Bioanal. Chem. 2015, 407, 8673-8679.

Conzález, A. J.; Blanco, G. D.; Arias, A. P.; Pello, P. J.; Ríos, L. N.; Busto, E.; Cotor, F. V.; Gutiérrez, A. M. D. Analysis of beer volatiles by polymeric imidazolium-solid phase microextraction coatings: synthesis and characterization of polymeric imidazolium ionic liquids. J. Chromatogr. A 2013, 1305, 35-40.

He, Y.; Pohl, J.; Engel, R.; Rothman, L.; Thomas, M. Preparation of ionic liquid based solid-phase microextraction fiber and its application to forensic determination of methamphetamine and amphetamine in human urine. J. Chromatogr. A 2009, 1216, 4824-4830.

Ho, T. D.; Canestraro, A. J.; Anderson, J. L. Ionic liquids in solid-phase microextraction: a review. Anal. Chim. Acta 2011, 695, 18-43.

Ho, T. D.; Yu, H.; Cole, W. T. S.; Anderson, J. L. Ultraviolet photoinitiated on-fiber copolymerization of ionic liquid sorbent coatings for headspace and direct immersion solid-phase microextraction. Anal. Chem. 2012a, 84, 9520-9528. 
Ho, T. T.; Chen, C. Y.; Li, Z. G.; Yang, T. C. C.; Lee, M. R. Determination of chlorophenols in landfill leachate using headspace sampling with ionic liquid-coated solid-phase microextraction fibers combined with gas chromatography-mass spectrometry. Anal. Chim. Acta 2012b, 712, $72-77$.

Ho, T. D.; Toledo, B. R.; Hantao, L. W.; Anderson, J. L. Chemical immobilization of crosslinked polymeric ionic liquids on nitinol wires produces highly robust sorbent coatings for solid-phase microextraction. Anal. Chim. Acta 2014a, 843, 18-26.

Ho, T. D.; Zhang, C.; Hantao, L. W.; Anderson, J. L. Ionic liquids in analytical chemistry: fundamentals, advances, and perspectives. Anal. Chem. 2014b, 86, 262-285.

Hsieh, Y. N.; Huang, P. C.; Sun, I. W.; Whang, T. J.; Hsu, C. Y.; Huang, H. H.; Kuei, C. H. Nafion membrane-supported ionic liquid-solid phase microextraction for analyzing ultra trace PAHs in water samples. Anal. Chim. Acta 2006, 557, 321-328.

$\mathrm{Hu}$, X.; Dai, G.; Huang, J.; Ye, T.; Fan, H., Youwen, T. Molecularly imprinted polymer coated on stainless steel fiber for solid-phase micro extraction of chloroacetanilide herbicides in soybean and corn. J. Chromatogr. A 2010, 1217, 5875-5882.

Huang, K. P.; Wang, C. R.; Huang, B. Y.; Liu, C. Y. Preparation and application of ionic liquid-coated fused-silica capillary fibers for solid-phase microextraction. Anal. Chim. Acta 2009, 645, 42-47.

Huang, S.; Zhu, F.; Jiang, R.; Zhou, S.; Zhu, D.; Liu, H.; Ouyang, G. Determination of eight pharmaceuticals in an aqueous sample using automated derivatization solid-phase microextraction combined with gas chromatography-mass spectrometry. Talanta 2015, 136, 198-203.

Jiménez, D. I.; Zafra, G. A.; Ballesteros, O.; Navalon, A. Analytical methods for the determination of personal care products in human samples: an overview. Talanta $\mathbf{2 0 1 4}, \mathbf{1 2 9}, 448-458$.

Kasprzyk, H. B.; Dinsdale, R. M.; Cuwy, A. J. Multiresidue methods for the analysis of pharmaceuticals, personal care products and illicit drugs in surface water and wastewater by solid-phase extraction and ultra performance liquid chromatography-electrospray tandem mass spectrometry. Anal. Bioanal. Chem. 2008, 391, 1293-1308.

Kataoka, H.; Saito, K. Recent advances in SPME techniques in biomedical analysis. J. Pharm. Biomed. Anal. 2011, 54, 926-950.

Kim, D.; Han, J.; Choi, Y. On-line solid-phase microextraction of triclosan, bisphenol A, chlorophenols, and selected pharmaceuticals in environmental water samples by high performance liquid chromatography-ultraviolet detection. Anal. Bioanal. Chem. 2013, 405, $377-387$.

Koster, E. H. M.; Crescenzi, C.; Den Hoedt, W.; Ensing, K.; de Jong, C. J. Fibers coated with molecularly imprinted polymers for solid-phase microextraction. Anal. Chem. 2001, 73, 3140-3145.

Li, J. R.; Sculley, J.; Zhou, H. C. Metal-organic frameworks for separations. Chem. Rev. 2012, 112, 869-932.

Li, Y.; Yang, Y.; Liu, H.; Wang, X.; Du, X. Fabrication of a novel Ti-TiO2-ZrO2 fiber for solid phase microextraction followed by high performance liquid chromatography for sensitive determination of UV filters in environmental water samples. Anal. Methods 2014a, 6 , $8519-8525$.

Li, Y.; Zhang, M.; Yang, Y.; Wang, X.; Du, X. Electrochemical in situ fabrication of titanium dioxide-nanosheets on a titanium wire as a novel coating for selective solid-phase microextraction. J. Chromatogr. A 2014b, 1358, 60-67.

Li, S.; Zhu, F.; Jiang, R.; Ouyang, G. Preparation and evaluation of amino modified graphene solid-phase microextraction fiber and its application to the determination of synthetic musks in water samples. J. Chromatogr. A 2016, 1429, 1-7.

Liao, K.; Mei, M.; Li, H.; Huang, X.; Wu, C. Multiple monolithic fiber solid-phase microextraction based on a polymeric ionic liquid with highperformance liquid chromatography for the determination of steroid sex hormones in water and urine. J. Sep. Sci. 2016, 39, 566-575.

Lima, C. P. C. F.; Barnes, B. B.; Santos, N. A. J.; Lancas, F. M.; Snow, N. H. Determination of steroids, caffeine and methylparaben in water using solid phase microextraction-comprehensive two dimensional gas chromatography-time of flight mass spectrometry. J. Chromatogr. A 2013, 1299, 126-130.

Lin, T.; Yu, S.; Chen, W. Occurrence, removal and risk assessment of pharmaceutical and personal care products (PPCPs) in an advanced drinking water treatment plant (ADWTP) around Taihu Lake in China. Chemosphere 2016, 152, 1-9.

Lirio, S.; Liu, W. L.; Lin, C. L.; Lin, C. H.; Huang, H. Y. Aluminum based metal-organic framework-polymer monolith in solid-phase microextraction of penicillins in river water and milk samples. J. Chromatogr. A 2016, 1428, 236-245.

Liu, J.; Li, N.; Jiang, G.; Liu, J.; Jönsson, J. A.; Wen, M. Disposable ionic liquid coating for headspace solid-phase microextraction of benzene, toluene, ethylbenzene, and xylenes in paints followed by gas chromatography-flame ionization detection. J. Chromatogr. A 2005, 1066, 27-32.

Liu, H.; Liu, L.; Xiong, Y.; Yang, X.; Luan, T. Simultaneous determination of UV filters and polycyclic musks in aqueous samples by solid-phase microextraction and gas chromatography-mass spectrometry. J. Chromatogr. A 2010a, 1217, 6747-6753.

Liu, M.; Zhou, X.; Chen, Y.; Liu, H.; Feng, X.; Qiu, G.; Liu, F.; Zeng, Z. Innovative chemically bonded ionic liquids-based sol-gel coatings as highly porous, stable and selective stationary phases for solid phase microextraction. Anal. Chim. Acta 2010b, 683, 96-106.

Liu, Q.; Shi, J.; Jiang, C. Application of graphene in analytical simple preparation. Trends Anal. Chem. 2012a, 37, 1-11.

Liu, X.; Wang, X.; Tan, F.; Zhao, H.; Quan, X.; Chen, J.; Li, L. An electrochemically enhanced solid-phase microextraction approach based on molecularly imprinted polypyrrole/multi-walled carbon nanotubes composite coating for selective extraction of fluoroquinolones in aqueous samples. Anal. Chim. Acta 2012b, 727, 26-33.

Liu, W. L.; Lirio, S.; Yang, Y.; Wu, L. T.; Hsiao, S. Y.; Huang, H. Y. A poly (alkyl methacrylate-divinylbenzene-vinylbenzyl trimethyl ammonium chloride) monolithic column for solid-phase microextraction. J. Chromatogr. A 2015, 1395, 32-40.

López, D. J.; Pino, V.; Anderson, J. L.; Graham, C. M.; Afonso, A. M. Determination of water pollutants by direct-immersion solid-phase microextraction using polymeric ionic liquid coatings. J. Chromatogr. A 2010a, 1217, 1236-1243.

López, D. J.; Pino, V.; Meng, Y.; Anderson, J. L.; Afonso, A. M. Utilization of a benzyl functionalized polymeric ionic liquid for the sensitive determination of polycyclic aromatic hydrocarbons; parabens and alkylphenols in waters using solid-phase microextraction coupled to gas chromatography-flame ionization detection. J. Chromatogr. A 2010b, 1217, 7189-7197.

Lord, H. L.; Rajabi, M.; Safari, S.; Pawliszyn, J. Development of immunoaffinity solid phase microextraction probes for analysis of sub $\mathrm{ng} / \mathrm{mL}$ concentrations of 7 aminoflunitrazepam in urine. J. Pharm. Biomed. Anal. 2016, 40, 769-780.

Ma, X.; Li, Q.; Yuan, D. Determination of endocrine-disrupting compounds in water by carbon nanotubes solid-phase microextraction fiber coupled online with high performance liquid chromatography. Talanta 2011, 85, 2212-2217. 
Machado, S.; Goncalves, C.; Cunh, E.; Guimarães, A.; Alpendurada, M. F. New developments in the analysis of fragrances and earthy-musty compounds in water by solid-phase microextraction (metal alloy fibre) coupled with gas chromatography (tandem) mass spectrometry. Talanta 2011, 84, 1133-1140.

McClellan, K.; Halden, R. U. Pharmaceuticals and personal care products in archived U.S. biosolids from the 2001 EPA national sewage sludge survey. Water Res. 2010, 44, 658-668.

Mehdinia, A.; Aziz, Z. M. O. Advances for sensitive, rapid and selective extraction in different configurations of solid-phase microextraction. Trends Anal. Chem. 2013a, 51, 13-22.

Mehdinia, A.; Aziz, Z. M. O. Recent advances in nanomaterials utilized in fiber coatings for solid-phase microextraction. Trends Anal. Chem. 2013b, 42, 205-215.

Mei, M.; Huang, X.; Yuan, D. Multiple monolithic fiber solid-phase microextraction: a new extraction approach for aqueous samples. J. Chromatogr. A 2014, 1345, 29-36.

Mei, M.; Huang, X.; Liao, K.; Yuan, D. Sensitive monitoring of benzoylurea insecticides in water and juice samples treated with multiple monolithic fiber solid-phase microextraction and liquid chromatographic analysis. Anal. Chim. Acta 2015a, 860, 29-36.

Mei, M.; Yu, J.; Huang, X.; Li, H.; Lin, L.; Yuan, D. Monitoring of selected estrogen mimics in complicated samples using polymeric ionic liquidbased multiple monolithic fiber solid-phase microextraction combined with high-performance liquid chromatography. J. Chromatogr. $\mathrm{A}$ 2015b, 1385, 12-19.

Meng, Y.; Anderson, J. L. Tuning the selectivity of polymeric ionic liquid sorbent coatings for the extraction of polycyclic aromatic hydrocarbons using solid-phase microextraction. J. Chromatogr. A 2010, 1217, 6143-6152.

Meng, Y.; Pino, V.; Anderson, J. L. Role of counteranions in polymeric ionic liquid-based solid-phase microextraction coatings for the selective extraction of polar compounds. Anal. Chim. Acta 2011, 687, 141-149.

Merkle, S.; Kleeberg, K. K.; Fritsche, J. Recent developments and applications of solid phase microextraction (SPME) in food and environmental analysis - a review. Chromatography 2015, 2, 293-381.

Montesdeoca, E. S.; Torres, P. M. E.; Sosa, F. Z.; Santana, R. J. J. Solid-phase microextraction with micellar desorption and HPLC-fluorescence detection for the analysis of fluoroquinolones residues in water samples. Anal. Bioanal. Chem. 2009, 394, 927-935.

Naccarato, A.; Cionfriddo, E.; Sindona, G.; Tagarelli, A. Simultaneous determination of benzothiazoles, benzotriazoles and benzosulfonamides by solid phase microextraction-gas chromatography-triple quadrupole mass spectrometry in environmental aqueous matrices and human urine. J. Chromatogr. A 2014, 1338, 164-173.

Negreira, N.; Rodríguez, I.; Ramil, M.; Rubí, E.; Cela, R. Sensitive determination of salicylate and benzophenone type UV filters in water samples using solid-phase microextraction, derivatization and gas chromatography tandem mass spectrometry. Anal. Chim. Acta 2009, 638, $36-44$.

Nieto, M. A.; Romero, R.; Romero. A.; Valverde, J. L. Carbon nanospheres: synthesis, physicochemical properties and applications. J. Mater. Chem. 2011, 21, 1664-1672.

Oliveira, S. T.; Murphy, M.; Mendola, N.; Wong, V.; Carlson, D.; Waring, L. Characterization of pharmaceuticals and personal care products in hospital effluent and waste water influent/effluent by direct-injection LC-MS-MS. Sci. Total Environ. 2015, 518, 459-478.

Papageorgiou, M.; Kosma, C.; Lambropoulou, D. Seasonal occurrence, removal, mass loading and environmental risk assessment of 55 pharmaceuticals and personal care products in a municipal wastewater treatment plant in Central Greece. Sci. Total Environ. 2016, 543, 547-569.

Pan, J.; Zhang, C.; Zhang, Z.; Li, G. Review of online coupling of sample preparation techniques with liquid chromatography. Anal. Chim. Acta 2014, 815, 1-15.

Pawliszyn, J. Solid Phase Microextraction: Theory and Practice. WILEY-VCH: New York, 2010.

Płotka, W. J.; Szczepanska, N.; De la Guardia, M.; Namiesnik, J. Miniaturized solid-phase extraction techniques. Trends Anal. Chem. 2015, 73, 19-38.

Poole, C. F.; Lenca, N. Green sample-preparation methods using room-temperature ionic liquids for the chromatographic analysis of organic compounds. Trends Anal. Chem. 2015, 71, 144-156.

Regueiro, J.; Becerril, E.; Garcia, J. C.; Llompart, M. Trace analysis of parabens, triclosan and related chlorophenols in water by headspace solid-phase microextraction with in situ derivatization and gas chromatography-tandem mass spectrometry. J. Chromatogr. A 2009, 1216, 4693-4702.

Robles, M. J.; Gilbert, L. B.; Garcia, R. J. F.; Molina, D. A. Comparative evaluation of liquid-liquid extraction, solid-phase extraction and solidphase microextraction for the gas chromatography-mass spectrometry determination of multiclass priority organic contaminants in wastewater. Talanta 2013, 117, 382-391.

Sarafraz, Y., Amiri, A.; Rounaghi, G.; Eshtiagh, H. H. Determination of non steroidal anti-inflammatory drugs in water samples by solid-phase microextraction based sol-gel technique using poly(ethylene glycol) grafted multi-walled carbon nanotubes coated fiber. Anal. Chim. Acta 2012, 720, 134-141.

Sarafraz, Y. A.; Razavi, N. Application of molecularly-imprinted polymers in solid-phase microextraction techniques. Trends Anal. Chem. 2015, 73, 81-90.

Shen, J. Y.; Chang, M. S.; Yang, S. H.; Wu, G. J. Simultaneous determination of triclosan, triclocarban, and transformation products of triclocarban in aqueous samples using solid-phase micro-extraction-HPLC-MS/MS. J. Sep. Sci. 2012, 35, 2544-2552.

Shi, F.; Liu, J.; Liang, K.; Liu, R. Tris(pentafluoroethyl)trifluorophosphate-based ionic liquids as advantageous solid-phase micro-extraction coatings for the extraction of organophosphate esters in environmental waters. J. Chromatogr. A 2016, 1447, 9-16.

Sigma Aldrich. 2017. https://www.sigmaaldrich.com/catalog (accessed November 6, 2017).

Song, W.; Guo, M.; Zhang, Y.; Zhang, M.; Wang, X.; Du, X. Fabrication and application of zinc-zinc oxide nanosheets coating on an etched stainless steel wire as a selective solid-phase microextraction fiber. J. Chromatogr. A 2015, 1384, 28-36.

Souza, E. A. S.; Risticevic, S.; Pawliszyn, J. Recent trends in SPME concerning sorbent materials, configurations and in vivo applications. Trends Anal. Chem. 2013, 43, 24-36. 
Souza, S. C.; Rombaldi, C.; De Oliveira, A. J. L.; Cardoso, M. L.; Cilberto, P. E. Multi-residue method for determination of 58 pesticides, pharmaceuticals and personal care products in water using solvent demulsification dispersive liquid-liquid microextraction combined with liquid chromatography-tandem mass spectrometry. Talanta 2016, 146, 676-688.

Spietelun, A.; Pilarczyk, A.; Kloskowski, A.; Namiesnik, J. Current trends in solid-phase microextraction (SPME) fibre coatings. Chem. Soc. Rev. 2010, 39, 4524-4537.

Sun, M.; Bu, Y.; Feng, J.; Luo, C. Graphene oxide reinforced polymeric ionic liquid monolith solid-phase microextraction sorbent for highperformance liquid chromatography analysis of phenolic compounds in aqueous environmental samples. J. Sep. Sci. 2016, 39, 375-382.

Tan, T. Y.; Basheer, Ch.; Yan, A. M. J.; Kee, L. H. Electroenhanced solid-phase microextraction of methamphetamine with commercial fibers. J. Chromatogr. A 2013, 1297, 12-16.

Tanoue, R.; Nomiyama, K.; Nakamura, H.; Hayashi, T.; Kim, J.; Isobe, T.; Shinohara, R.; Tanabe, S. Simultaneous determination of polar pharmaceuticals and personal care products in biological organs and tissues. J. Chromatogr. A 2014, 1355, 193-205.

Teo, T. L. L.; Coleman, H. M.; Khan, S. J. Occurrence and daily variability of pharmaceuticals and personal care products in swimming pools. Environ. Sci. Pollut. Res. 2016, 23, 6972-6981.

Terzopoulou, Z.; Papageorgiou, M.; Kyzas, G. Z.; Bikiaris, D. N.; Lambropoulou, D. A. Preparation of molecularly imprinted solid-phase microextraction fiber for the selective removal and extraction of the antiviral drug abacavir in environmental and biological matrices. Anal. Chim. Acta 2016, 913, 63-75.

Tian, J.; Xu, J.; Zhu, F.; Lu, T.; Su, C.; Ouyang, G. Application of nanomaterials in sample preparation. J. Chromatogr. A 2013, 1300, 2-16.

Torres, P. M. E.; Sosa, Z.; Santana, R. J. J. Coupling of solid-phase microextraction with micellar desorption and high performance liquid chromatography for the determination of pharmaceutical residues in environmental liquid samples. Biomed. Chromatogr. 2009; 23, 1175-1185.

Turiel, E.; Martin, E. A. Molecularly imprinted polymers for solid-phase microextraction. J. Sep. Sci. 2009, 32, 3278-3284.

Unceta, N.; Sampedro, M. C.; Abu, B. N. K.; Cómez, C. A.; Coicole, M. A.; Barrio, R. J. Multi-residue analysis of pharmaceutical compounds in wastewaters by dual solid-phase microextraction coupled to liquid chromatography electrospray ionization ion trap mass spectrometry. J. Chromatogr. A 2010, 1217, 3392-3399.

Vallecillos, L.; Borrull, F.; Pocurull, E. An automated headspace solid phase microextraction followed by gas chromatography-mass spectrometry method to determine macrocyclic musk fragrances in wastewater samples. Anal. Bioanal. Chem. 2013a, 405, 9547-9554.

Vallecillos, L.; Pocurull, R.; Borrull, F. A simple and automated method to determine macrocyclic musk fragrances in sewage sludge samples by headspace solid-phase microextraction and gas chromatography-mass spectrometry. J. Chromatogr. A 2013b, 1314, 38-43.

Vasapollo, G.; Del Sole, R.; Mergola, L.; Lazzoi, M. R.; Scardino, A.; Scorrano, S.; Mele, G. Molecularly imprinted polymers: present and future prospective. Int. J. Mol. Sci. 2011, 12, 5908-5945.

Vičkačkaitè, V.; Padarauskas, A. lonic liquids in microextraction techniques. Cent. Eur. J. Chem. 2012, 10, 652-674.

Wang, J. X.; Jiang, D. Q.; Gu, Z. Y.; Yan, X. P. Multiwalled carbon nanotubes coated fibers for solid-phase microextraction of polybrominated diphenyl ethers in water and milk samples before gas chromatography with electron-capture detection. J. Chromatogr. A 2006, 1137, 8-14.

Wang, Y. C.; Ding, W. H. Determination of synthetic polycyclic musks in water by microwave-assisted headspace solid-phase microextraction and gas chromatography mass spectrometry. J. Chromatogr. A 2009, 1216, 6858-6863.

Wang, X.; Liu, J.; Liu, A.; Liu, Q.; Du, X.; Jiang, C. Preparation and evaluation of mesoporous cellular foams coating of solid-phase microextraction fibers by determination of tetrabromobisphenol A, tetrabromobisphenol S and related compounds. Anal. Chim. Acta 2012, 753, $1-7$.

Wang, C.; Yang, L.; Li, N.; Zhang, X.; Cuo, Y.; Li, C. Development of immunoaffinity solid phase microextraction rods for analysis of three estrogens in environmental water samples. J. Chromatogr. B 2017, 1061, 41-48.

Wu, S. F.; Ding, W. H. Fast determination of synthetic polycyclic musks in sewage sludge and sediments by microwave-assisted headspace solid-phase microextraction and gas chromatography-mass spectrometry. J. Chromatogr. A 2010, 1217, 2776-2781.

Xu, J.; Zheng, J.; Tian, J.; Zhu, F.; Zeng, F.; Su, C.; Ouyang, C. New materials in solid-phase microextraction. Trends Anal. Chem. 2013a, 47, 68-83.

Xu, S.; Zhang, X.; Sun, Y.; Yu, D. Microwave-assisted preparation of monolithic molecularly imprinted polymeric fibers for solid phase microextraction. Analyst 2013b, 138, 2982-2987.

$\mathrm{Xu}, \mathrm{R}$.; Lee, H. K. Application of electro-enhanced solid phase microextraction combined with gas chromatography-mass spectrometry for the determination of tricyclic antidepressants in environmental water samples. J. Chromatogr. A 2014, 1350, 15-22.

Yang, Y.; Li, Y.; Liu, H.; Wang, X.; Du, X. Electrodeposition of gold nanoparticles onto an etched stainless steel wire followed by a selfassembled monolayer of octanedithiol as a fiber coating for selective solid-phase microextraction. J. Chromatogr. A 2014, $1372,25-33$.

Yılmazcan, O.; Kanakaki, C.; Izgi, B.; Rosenberg, E. Fast determination of octinoxate and oxybenzone UV filters in swimming pool waters by gas chromatography/mass spectrometry after solid-phase microextraction. J. Sep. Sci. 2015, 38, 2286-2297.

You, L.; Nguyen, V. T.; Pal, A.; Chen, H.; He, Y.; Reinhard, M.; Yew-Hoong, G. K. Investigation of pharmaceuticals, personal care products and endocrine disrupting chemicals in a tropical urban catchment and the influence of environmental factors. Sci. Total Environ. 2015, 536, 955-963.

Yu, H.; Ho, T. D.; Anderson, J. L. Ionic liquid and polymeric ionic liquid coatings in solid-phase microextraction. Trends Anal. Chem. 2013, 45, 219-232.

Yu, H.; Merib, J.; Anderson, J. L. Crosslinked polymeric ionic liquids as solid-phase microextraction sorbent coatings for high performance liquid chromatography. J. Chromatogr. A 2016, 1438, 10-21.

Zhang, H.; Lee, H. K. Simultaneous determination of ultraviolet filters in aqueous samples by plunger-in-needle solid-phase microextraction with graphene-based sol-gel coating as sorbent coupled with gas chromatography-mass spectrometry. Anal. Chim. Acta 2012a, 742, 67-73.

Zhang, Y.; Wang, X.; Lin, C.; Fang, G.; Wang, S. A novel SPME fiber chemically linked with 1-vinyl-3-hexadecylimidazolium hexafluorophosphate ionic liquid coupled with CC for the simultaneous determination of pyrethroids in vegetables. Chromatographia 2012b, 75 , 789-797.

Zhang, M.; Zeng, J.; Wang, Y.; Chen, X. Developments and trends of molecularly imprinted solid-phase microextraction. J. Chromatogr. Sci. 2013, 51, 577-586. 
Zhang, C.; Bhargava, G.; Elwell, M. D.; Parasher, S.; Zhou, B.; Yates, D.; Knoke, I.; Neitzel, I.; Gogotsi, Y. Hollow graphitic carbon nanospheres: synthesis and properties. J. Mater. Sci. 2014, 49, 1947-1956.

Zhao, F.; Meng, Y.; Anderson, J. L. Polymeric ionic liquids as selective coatings for the extraction of esters using solid-phase microextraction. J. Chromatogr. A 2008, 1208, 1-9.

Zheng, J.; Wang, K.; Luo, E.; Wu, D.; Zhu, F.; Jiang. R.; Su, C.; Wei, C.; Ouyang, G. Monodisperse microporous carbon nanospheres: an efficient and stable solid phase microextraction coating material. Anal. Chim. Acta 2015, 884, 44-51.

Zhou, X.; Shao, X.; Shu, J.; Liu, M.; Liu, H.; Feng, X; Liu, F. Thermally stable ionic liquid-based sol-gel coating for ultrasonic extraction-solidphase microextraction-gas chromatography determination of phthalate esters in agricultural plastic films. Talanta 2012, 89, 129-135. 